\title{
Перспективы развития строительного материаловедения
}

\author{
Е.В.Королев, СПбГАСУ, Санкт-Петербург
}

В работе описаны позиционирование и перспективы развития строительного материаловедения. Показано, что его развитие базируется на новых знаниях фундаментальных и смежных прикладных наук. При этом высокая вариативность свойств компонентов значительно ограничивает возможность естественного применения фундаментальных знаний о механизмах их взаимодействия для описания процессов структурообразования материала.

Вместе с этим получение новых знаний в строительном материаловедении основано на установлении особенностей механизмов структурообразования материалов с учётом изменчивости характеристик их компонентов.

Расширены системные представления о строительных материалах. Такие композиты являются сложными техническими системами, способными к самоорганизации в неравновесных условиях. Такое понимание строительных материалов предполагает наличие синергетического эффекта. Предложен метод определения синергетического эффекта от влияния управляющих факторов на параметры структуры и свойства материала - метод «последовательных смещений и варьирования». Этот метод дополняет метод математического планирования эксперимента и пригоден для определения областей факторного пространства факторов для проведения подробных исследований и установления параметров структуры и особенностей структурообразования материала, приводящих к возникновению синергетического эффекта (начала формирования строительного материала как технической системы).

Ключевые слова: строительное материаловедение, строительные материалы, системный анализ, синергетический эффект, новое технологическое решение, новые знания, алгоритм синтеза материалов.

\section{Prospects for the Development of Construction Materials} Science

\section{E.V.Korolev, SPbGASU, St.-Petersburg}

This paper is devoted to two similar objectives: to properly position the role of materials science and to outline probable directions of its future development. The latter is based on recent progress in fundamental and related applied sciences. At the same time, the proper usage of fundamental and applied sciences results' is quite limited due to highly variable properties of the components. This significantly limits the application of already obtained knowledge related to the mechanisms of interaction between the components during the structure formation processes.
Contemporaneously, the acquisition of new knowledge in construction materials science is based on the discovering the features of the structure formation mechanisms of materials, while considering the variability the previously being mentioned difference in characteristics.

In this article the author had expanded the systemic concepts in the construction materials science. As the typical complex technical systems, composite materials are able to selforganize even in non-equilibrium conditions. This assessment suggests the existence of synergistic effect. The method which can be used for the evaluation of the mentioned synergistic effect between control factors and structure's parameters, namely "successive displacements and variations" method - was offered. The method complements the well-known experimental design methods and is suitable for determination the areas of the factor space in which the detailed studies should be performed to determine the dependences between features of structure and process of the material's structure formation. These dependencies, in turn, can show up the emergence of a synergistic effect - the building material is starting to be form as a technical system.

Keywords: building materials science, building materials, systems analysis, synergistic effect, novel technological solution, new knowledge, algorithms for materials synthesis.

Строительное материаловедение, тесно связанное с материаловедением в целом ${ }^{1}$, усилиями ряда исследователей продолжает активно развиваться. Его формирование сопряжено с закономерным развитием фундаментальных и смежных прикладных наук. Отнесение строительного материаловедения к области прикладных наук предопределяет его назначение как научной дисциплины, направленной на разработку новых технологических решений или технологий, основанных на новых знаниях, полученных фундаментальными науками ${ }^{2}$. Это, безусловно, не означает, что новые знания не могут быть получены в ходе проведения исследований при разработке нового технологического решения. Видится, что использование компонентов с широкими диапазонами варьирования как геометрических характеристик, так и химического, минералогического и/или фазового составов,

${ }^{1}$ См. паспорт научной специальности 05.16.05 Материаловедение (источник: https://vak.minobrnauki.gov.ru/searching\#tab=_tab:materials ).

${ }^{2}$ Федеральный закон от 23.08.1996 г. № 127-Ф3 «0 науке и государственной научно-технической политике» (ред. от 25.05.2020). 
является одновременно «слабой» стороной и достоинством строительного материаловедения. Слабость заключается в том, что затруднительно осуществить простой перенос новых знаний, полученных фундаментальными науками, на наблюдаемые процессы, явления или закономерности строительного материаловедения, а достоинство состоит в получении новых знаний о дополнительных характерных особенностях в механизмах взаимодействия таких сложных компонентов и в возникновении эмерджентности ${ }^{3}$ у материала.

Важным является степень детализации в разработке механизмов структурообразования. Очевидно, что при наличии высокой вариативности в свойствах компонентов, предопределяющей возможность реализации нескольких механизмов их взаимодействия, избыточная детализация не предоставит дополнительной информации для разработки способа управления структурообразованием материала. Этот способ является основой для разработки новой технологии или технологического решения, направленных на получение строительных материалов с эксплуатационными свойствами, превышающими аналог (технический уровень). При этом вследствие практико-ориентированного характера строительного материаловедения необходимо обеспечить экономическую эффективность материала.

Укажем наиболее значимые, по мнению автора, направления в развитии строительного материаловедения.

- Теория протекания и фрактальная геометрия в теории композиционных строительных материалов. Эти две фундаментальные концепции являются весьма полезными для описания влияния содержания дисперсной фазы на структурно-чувствительные свойства композитов [1-6]. Созданная на этих теориях научная концепция позволила установить оптимальные диапазоны содержания дисперсной фазы в зависимости от геометрических характеристик её частиц, осуществить анализ различных фазовых переходов на всех этапах структурообразования материала.

- Геоника (геомиметика) - новое направление, сосредоточенное на «исследовании объектов неорганического мира с целью создания новых технологий производства материалов и оптимизацию системы «человек - материал - среда обитания», позволяющее преодолеть грандиозный разрыв между показателями свойств природных и техногенных материалов [7]. Это существенно расширяет принцип технологического соответствия, предложенный 0.П. Мчедловым-Петросяном [8]. Предложен научный подход к проектированию материалов с заданными параметрами структуры и эксплуатационных свойств, основанный на принципах кибернетики. Сформулирован закон «сродства структур», в сущности, аналогичный эмпирическому правилу химии: «подобное растворяется в подобном», а именно: «проектирование слоистых композитов

${ }^{3}$ Эмерджентность - появление у системы свойств, не присущих свойствам её компонентов; несводимость свойств системы к сумме свойств её компонентов (https://ru.wikipedia.org/wiki/Эмерджентность). и ремонтных систем на нано- , микро- и макроуровне аналогичных базовой матрице».

- Системный анализ в строительном материаловедении [9-17]. Строительное материаловедение всегда базируется на знаниях, полученных в фундаментальных и прикладных науках. Однако одного только понимания сложности строительных материалов как технических систем недостаточно для построения чётких алгоритмов их анализа и синтеза (проектирования). За многолетнюю практику развития системного анализа, как междисциплинарного метода познания, разработано множество приёмов анализа и синтеза разнообразных систем (военных, технических, социально-экономических и т.д.). Каждому такому приёму вследствие сложности и наличия индивидуальных особенностей свойственна уникальность. Для строительных материалов доказано наличие системных признаков, относящих их к сложным техническим системам, а также разработаны алгоритмы их анализа и синтеза.

- Управление физико-химическими процессами на границе раздела фаз и техногенный метасоматоз. Одним из следствий системного рассмотрения строительных композитов является выделение ключевой функции межфазных взаимодействий. Интенсивность этих взаимодействий приводит к формированию «плёночной фазы» матричного материала со свойствами, отличающимися от свойств матрицы в объёмном состоянии [6]. Интенсивность взаимодействия на межфазной поверхности оценивают величиной краевого угла смачивания; при использовании стандартных жидкостей можно произвести оценку и классификацию минерального сырья по критерию энергоёмкости [18-26]. Решение прикладной задачи по определению краевого угла смачивания в условиях протекания различных конкурирующих процессов пока ещё не завершено. Однако её решение имеет весьма ценное значение при проведении процедур выбора компонентов, оценке интенсивности процессов на границе раздела фаз, установлении корреляционных зависимостей между указанными поверхностными явлениями и свойствами материала, а также для дальнейшего анализа структурообразования на начальном этапе и выявления управляющих факторов для формирования структуры и свойств материала.

Связанным с активностью твёрдой поверхности является техногенный метасоматоз, указывающий на протекание необратимых процессов изменения параметров структуры и свойств материала при его взаимодействии с окружающей средой. Развитие этого направление позволит уточнить и в дальнейшем управлять процессами структурообразования материала в эксплуатационный период (долговечностью).

- Наномодифицирование строительных материалов на минеральных вяжущих веществах. Существенные обобщения результатов, полученных различными коллективами исследователей, даны в серии публикаций Е.М. Чернышова и О.В. Артамоновой [27-33]. Опираясь на эти системные обобщения, устанавливающие взаимосвязь между достижениями строительного материаловедения, полученными ранее, треками реализа- 
ции принципов нанотехнологии, новыми экспериментальными данными и перспективами развития, возможно продолжить совершенствование научных основ синтеза первичных наноматериалов и управления структурообразованием композитов на минеральных вяжущих веществах посредством выбора химического состава и концентрации первичных наноматериалов.

- Бетоны нового поколения. Бетон - основной строительный материал, варьирование рецептуры которого позволяет обеспечить получение строительных конструкций и изделий с различными эксплуатационными свойствами и областями применения. В этом направлении строительного материаловедения исследования проводят большое количество исследователей, входящих в коллективы различных научных школ. В отдельную группу выделим разработки, направленные на получение бетонов нового поколения с низким удельным расходом портландцемента на единицу прочности [34-40]. Такие бетоны обладают прочностью при сжатии 120...150 МПа при удельном расходе портландцемента 2,5...5,0 кг/МПа. Такие результаты имеют очевидный технико-экономический эффект и достигаются посредством применения многокомпонентных оптимально подобранных составов, формирующих плотное «структурно-топологическое строение» материала.

Другими важными направлениями являются: применение биотехнологии в повышении эффективности строительных материалов и при разработке самовосстанавливающихся материалов [41-49], разработка и совершенствование методов определения долговечности строительных материалов [50-69], совершенствование и разработка новых физических методов повышения интенсивности межфазных взаимодействий [70-75], применение методов математического моделирования для получения новых знаний о структурообразовании строительных материалов [76-85] и др.

\section{Системный анализ и математика}

Как уже отмечалось, строительные материалы являются сложными техническими системами, появление эмерджентности у которых связано с межфазным взаимодействием. Часто для разработки нового технологического решения и анализа структурообразования необходимо привлекать знания и инструментарий других научных дисциплин. Многообразие условий эксплуатации и вариативность свойств компонентов и условий получения (синтеза) материала предопределяют как уникальность предлагаемого технологического решения, так и указывают на наличие типового алгоритма его исследования и разработки. Такой алгоритм имеет следующую последовательность действий:

- анализ технического задания. Часто техническое задание содержит информацию об области применения (условиях эксплуатации), а также граничные значения базовых свойств, которые предопределяют аналоги для разрабатываемого материала и базу для оценки технико-экономического эффекта предлагаемого технологического решения;

- выбор компонентов материала. Эта процедура направлена на сокращение количества вариантов решения по тех- ническому заданию. При её реализации может привлекаться информация как по имеющимся технологическим решениям или обоснованным областям применения компонентов (в том числе рекомендации производителей по применению новых соединений), так и объективно обоснованные гипотезы по совместному применению нескольких соединений или синтезированных новых веществ. Указанный пункт алгоритма имеет весьма важное значение не только для сокращения временных и материальных затрат при разработке нового технологического решения, но и позволяет аргументировано дополнять или развивать научные основы строительного материаловедения;

- декомпозиция системы критериев качества. На основе условий эксплуатации и по базовым свойствам проводится выделение полного перечня свойств материала, по которым можно в полном объёме произвести оценку качества разрабатываемого материала. Эти свойства классифицируются на две группы: интенсивные и экстенсивные свойства. Интенсивные (структурно-чувствительные) свойства - это свойства, величина которых зависит как от свойств и содержания компонентов, так и от межфазного взаимодействия. К таким свойствам относятся прочность, модуль упругости, проницаемость и т.д. Экстенсивные свойства - это свойства, величина которых зависит только от свойств и содержания компонентов. Межфазные взаимодействия оказывают незначительное влияние (в пределах ошибки измерения). К таким свойствам можно отнести среднюю плотность, теплоёмкость, теплопроводность и т.д.;

- определение управляющих факторов. К управляющим факторам относятся рецептурные и технологические факторы технологии, которые оказывают влияние на все интенсивные свойства. Определение управляющих факторов производится посредством декомпозиции каждого структурно-чувствительного свойства по фазам, явлениям и процессам с выделением наиболее часто повторяющихся фаз, явлений или процессов;

- экспериментально-статистические модели. На этом этапе алгоритма проводятся экспериментальные исследования для установления влияния управляющих факторов на свойства, определяющие качество материала. Для получения общих представлений о взаимосвязи факторов и свойств целесообразно использовать методы математического планирования эксперимента. Диапазоны варьирования рецептурных факторов ориентировочно можно оценить по величинам экстенсивных свойств, указанным в техническом задании.

Для интенсивных свойств после установления экспериментально-статистических моделей в областях фазовых переходов или оптимума в факторном пространстве факторов целесообразно провести дополнительные исследования. Целью этих исследований должно быть установление взаимосвязи «рецептурный фактор/технологический фактор - параметр структуры - свойство». При этом вид получаемых математических зависимостей должен иметь физическое и/или физико-химическое обоснование. Анализ таких зависимостей, вносимый физически обоснованные уточнения, установление отличий от ранее предложенных зависимостей, обоснование 
отличий в значениях эмпирических коэффициентов для исследуемой рецептуры может являться новыми знаниями и составлять научную новизну проводимых исследований и разработок;

- многокритериальная оптимизация. Полученные экспериментально-статистические модели влияния управляющих рецептурно-технологических факторов на качество материала используются для проведения многокритериальной оптимизации, назначение которой состоит в установлении диапазонов варьирования управляющих факторов для получения материала со свойствами, соответствующими или превосходящими требования, указанные в техническом задании или аналога. Целевой функцией такой оптимизации может быть обобщенный критерий качества, учитывающий все свойства материала, представленные как в техническом задании, так и выделенные при декомпозиции системы критериев качества. Часто используют аддитивно-мультипликативные функции, в которых влияние на качество материала отдельных групп свойств учитывается в виде аддитивной функции с соответствующими коэффициентами весомости, а влияние отдельного свойства в каждой из этих групп свойств - в виде мультипликативной функции. Каждое свойство представлено в виде частного критерия, расчёт которого производится относительно контрольного значения этого свойства, указанного в техническом задании или у аналога.

0бязательным условием (ограничением) является не только достижение качества материала, получаемого по разработанному новому научно обоснованному технологическому решению, но и достижение экономического эффекта, то есть осуществление технико-экономического обоснования. Это может быть проведено посредством расчёта коэффициента технико-экономической эффективности, который дополнительно может учитывать возможность реализации предлагаемого технологического решения [86];

- экспериментальная проверка и корректировка нового технологического решения. Этот этап является обязательным для проверки адекватности установленных диапазонов варьирования управляющих факторов и соответствия требованиям технического задания. Очевидно, что при наличии отклонений необходимо проведение корректирующих действий.

Дальнейшая систематизация и развитие строительного материаловедения как научной дисциплины возможно только при формализации технических задач и совершенствовании методов их решения. Такой подход обеспечит объективность и комплексность оценки предлагаемых технологических решений, их идентификацию и классификацию, преодоление эвристики доступности ${ }^{4}$, которая часто встречается в современных исследованиях, а также способствовать развитию теории строительных композитов [11].

\section{Новые знания и синергетический эффект}

Необходимо отметить, что даже при использовании формализованного подхода задача развития будет сталкиваться с естественными трудностями, связанными с вариативностью каждого технологического решения. Причем часто результатом применения разработанного технологического решения является создание таких условий структурообразования, при которых параметры структуры будут отличаться незначительно для материалов с примерно аналогичным уровнем качества. Отсюда следует, что достижение заданного уровня качества (значений эксплуатационных свойств) может быть обеспечено различным набором и диапазонами варьирования управляющих факторов. При определённых вариациях управляющих факторов может наблюдаться непропорциональное нелинейное влияние управляющих факторов на структурно-чувствительные свойства материала. Такие сочетания представляют определённый интерес для подробного изучения структурообразования и параметров структуры материала, результатом которого может быть новое знание 5 . Указанное следует из следующих соображений. Выделение большого перечня управляющих факторов (к ним могут относиться рецептура, свойства компонентов, параметры режима изготовления и т.д.) предопределяет получение сложной системы, в которой протекает множество конкурирующих процессов. Каждый из этих процессов может быть с достаточной точностью описан известными фундаментальными законами. Однако их выходные параметры будут существенно отличаться от значений, предсказанных теоретически, вследствие влияния других процессов. Взаимодействие процессов приводит к формированию определённых параметров структуры материала. При этом влияние каждого из факторов на процессы структурообразования является индивидуальным. Таким же индивидуальным является влияние различных сочетаний факторов, из которых фактический интерес представляют только сочетания с непропорциональным вкладом, указывающим на их взаимное усиление или ослабление.

Таким образом, для строительного материаловедения, кроме исследования новых явлений, новых процессов структурообразования, научный и практический интерес представляют управляющие факторы и их сочетания, которые оказывают непропорциональное нелинейное влияние на процессы структурообразования, формирующие параметры структуры и свойства материала. Научно обоснованное объяснение возникновения такого нелинейного влияния факторов с позиций изменения параметров процесса структурообразования и параметров структуры материала является научной новизной ${ }^{6}$.

Установление такого нелинейного влияния факторов может быть проведено посредством представления строительного материала не только как сложной технической

\footnotetext{
4 Эвристика доступности - это интуитивный процесс, в котором человек оценивает событие как более частое или более вероятное по степени лёгкости, с которой ассоциированные события приходят на ум, более вероятным или часто происходящим кажется то, что легче вспоминается (источник: httрs:// ru.wikipedia.org/wiki/Эвристика_доступности).

${ }^{5}$ Такое знание может также являться научной новизной диссертационной работы.
} 
системой, но и как синергетической системой, для которой характерны следующие свойства [87]:

1) нелинейность поведения;

2) наличие альтернативных путей развития (наличие точек бифуркации);

3) эволюция поведения и альтернативы определяются внешней средой;

4) эволюции подвержены элементы и связи между элементами.

Оценку нелинейности влияния управляющих факторов предлагается проводить по величине синергетического эффекта, возникающего только в открытых системах, способных к самоорганизации в неравновесных условиях, в проявлении которого принимают участие несколько элементов структуры (подсистем), взаимодействие которых приводит к самоорганизации (эмерджентное свойство), проявляющейся в скачкообразном (нелинейном) изменении характеристик (свойств) системы.

Количественную оценку синергетического эффекта предлагается производить в соответствии с методом «последовательных смещений и варьирования». Сущность метода заключается в последовательном варьировании выделенных управляющих факторов и установления влияния этого изменения на свойства материала. Графически сущность метода представлена на рисунке 1 . В диапазонах изменения управляющих факторов проводится последовательное изменение их величин: смещение от точки 1 к точке $k$, в каждой из которых проводится варьирование каждого фактора.

Нелинейное влияние выбранных $т$ управляющих факторов на каждое свойство на $k$-ом шаге можно представить в виде:

$$
f_{1, k}^{n_{1}^{( \pm)}} \times f_{2, k}^{n_{2}^{( \pm)}} \times f_{3, k}^{n_{3}^{( \pm)}} \times \ldots \times f_{m, k}^{n_{m}^{( \pm)}}=I_{j, k}^{( \pm)}
$$

где $f_{\mathrm{i}}$ - управляющий фактор; $n_{\mathrm{i}}$ - показатель степени; $I_{j}$ рассматриваемое свойство; знаками «+» и «-» обозначены увеличение или уменьшение величины $i$-го управляющего фактора, соответственно.

После нормировки к начальным значениям j-го свойства на $k$-ом шаге изменения управляющих факторов формула (1) примет вид:

$$
\left(\frac{f_{1, k}}{f_{1,0, k}}\right)^{n_{1}^{( \pm)}} \times\left(\frac{f_{2, k}}{f_{2,0, k}}\right)^{n_{2}^{( \pm)}} \times\left(\frac{f_{3, k}}{f_{3,0, k}}\right)^{n_{3}^{( \pm)}} \times \ldots \times\left(\frac{f_{m, k}}{f_{m, 0, k}}\right)^{n_{m}^{( \pm)}}=\frac{I_{j, k}^{( \pm)}}{I_{j, 0, k}} .
$$

Для свойств, величина которых должна быть минимизирована (например, пористость, массопоглощение, износ, истираемость и т.д.), формулу (2) необходимо представить в виде:

$$
\left(\frac{f_{1, k}}{f_{1,0, k}}\right)^{n_{1}^{( \pm)}} \times\left(\frac{f_{2, k}}{f_{2,0, k}}\right)^{n_{2}^{( \pm)}} \times\left(\frac{f_{3, k}}{f_{3,0, k}}\right)^{n_{3}^{( \pm)}} \times \ldots \times\left(\frac{f_{m, k}}{f_{m, 0, k}}\right)^{n_{m}^{( \pm)}}=\frac{I_{j, 0, k}}{I_{j, k}^{( \pm)}} .
$$

Изменение $i$-го фактора можно представить в виде:

$$
\begin{aligned}
& f_{i}^{(+)}=f_{i, 0}+\Delta f_{i} ; \\
& f_{i}^{(-)}=f_{i, 0}-\Delta f_{i} .
\end{aligned}
$$

где $\Delta f_{i}$ - приращение фактора.

\footnotetext{
${ }^{6}$ Расширение теоретических представлений о протекающих процессах или явлениях являетя теоретической значимостью диссертационной работы.
}

При последовательном варьировании факторов на $k$-ом шаге получим систему уравнений:

$$
\begin{aligned}
& \text { - для } f_{i}^{(+)} \text {: } \\
& \int\left(\frac{f_{1,0, k}+\Delta f_{1, k}}{f_{1,0, k}}\right)^{n_{1}^{(+)}} \times\left(\frac{f_{2,0, k}}{f_{2,0, k}}\right)^{n_{2}^{(+)}} \times\left(\frac{f_{3,0, k}}{f_{3,0, k}}\right)^{n_{3}^{(+)}} \times \ldots \times\left(\frac{f_{m, 0, k}}{f_{m, 0, k}}\right)^{n_{m}^{(+)}}=\frac{l_{1, k}^{(+)}\left(f_{1, k}\right)}{I_{j, 0, k}} \\
& \left(\frac{f_{1,0, k}}{f_{1,0, k}}\right)^{n_{1}^{(+)}} \times\left(\frac{f_{2,0, k}+\Delta f_{2, k}}{f_{2,0, k}}\right)^{n_{2}^{(+)}} \times\left(\frac{f_{3,0, k}}{f_{3,0, k}}\right)^{n_{3}^{(+)}} \times \ldots \times\left(\frac{f_{m, 0, k}}{f_{m, 0, k}}\right)^{n_{m}^{(+)}}=\frac{l_{1, k}^{(+)}\left(f_{2, k}\right)}{l_{j, 0, k}} \\
& \left\{\left(\frac{f_{1,0, k}}{f_{1,0, k}}\right)^{n_{1}^{(+)}} \times\left(\frac{f_{2,0, k}}{f_{2,0, k}}\right)^{n_{2}^{(+)}} \times\left(\frac{f_{3,0, k}+\Delta f_{3, k}}{f_{3,0, k}}\right)^{n_{3}^{(+)}} \times \ldots \times\left(\frac{f_{m, 0, k}}{f_{m, 0, k}}\right)^{n_{m}^{(+)}}=\frac{l_{i, k}^{(+)}\left(f_{3, k}\right)}{l_{j, 0, k}}\right. \\
& \left(\left(\frac{f_{1,0, k}}{f_{1,0, k}}\right)^{n_{1}^{(+)}} \times\left(\frac{f_{2,0, k}}{f_{2,0, k}}\right)^{n_{2}^{(+)}} \times\left(\frac{f_{3,0, k}}{f_{3,0, k}}\right)^{n_{3}^{(+)}} \times \ldots \times\left(\frac{f_{m, 0, k}+\Delta f_{m, k}}{f_{m, 0, k}}\right)^{n_{m}^{(+)}}=\frac{l_{j, k}^{(+)}\left(f_{m, k}\right)}{l_{j, 0, k}}\right. \\
& \text { - для } f_{i}^{(-)} \text {: } \\
& \left(\left(\frac{f_{1,0, k}+\Delta f_{1, k}}{f_{1,0, k}}\right)^{n_{1}^{(-)}} \times\left(\frac{f_{2,0, k}}{f_{2,0, k}}\right)^{n_{2}^{(-)}} \times\left(\frac{f_{3,0, k}}{f_{3,0, k}}\right)^{n_{3}^{(-)}} \times \ldots \times\left(\frac{f_{m, 0, k}}{f_{m, 0, k}}\right)^{n_{m}^{(-)}}=\frac{l_{j, k}^{(-)}\left(f_{1, k}\right)}{I_{j, 0, k}}\right. \\
& \left(\frac{f_{1,0, k}}{f_{1,0, k}}\right)^{n_{1}^{(-)}} \times\left(\frac{f_{2,0, k}+\Delta f_{2, k}}{f_{2,0, k}}\right)^{n_{2}^{(-)}} \times\left(\frac{f_{3,0, k}}{f_{3,0, k}}\right)^{n_{3}^{(-)}} \times \ldots \times\left(\frac{f_{m, 0, k}}{f_{m, 0, k}}\right)^{n_{m}^{(-)}}=\frac{l_{j, k}^{(-)}\left(f_{2, k}\right)}{l_{j, 0, k}} \\
& \left(\frac{f_{1,0, k}}{f_{1,0, k}}\right)^{n_{1}^{(-)}} \times\left(\frac{f_{2,0, k}}{f_{2,0, k}}\right)^{n_{2}^{(-)}} \times\left(\frac{f_{3,0, k}+\Delta f_{3, k}}{f_{3,0, k}}\right)^{n_{3}^{(-)}} \times \ldots \times\left(\frac{f_{m, 0, k}}{f_{m, 0, k}}\right)^{n_{m}^{(-)}}=\frac{l_{i, k}^{(-)}\left(f_{3, k}\right)}{l_{j, 0, k}} \\
& \left(\left(\frac{f_{1,0, k}}{f_{1,0, k}}\right)^{n_{1}^{(-)}} \times\left(\frac{f_{2,0, k}}{f_{2,0, k}}\right)^{n_{2}^{(-)}} \times\left(\frac{f_{3,0, k}}{f_{3,0, k}}\right)^{n_{3}^{(-)}} \times \ldots \times\left(\frac{f_{m, 0, k}+\Delta f_{m, k}}{f_{m, 0, k}}\right)^{n_{m}^{(-)}}=\frac{l_{i, k}^{(-)}\left(f_{m, k}\right)}{l_{j, 0, k}}\right.
\end{aligned}
$$

По формулам (4) и (5) можно вычислить значения показателей степени:

$$
n_{i, k}^{( \pm)}=\frac{\ln \left(I_{j}\left(f_{i, k}^{( \pm)}\right) / I_{j, 0, k}\right)}{\ln \left(1 \pm \delta f_{i}\right)}
$$

где $\delta f_{\mathrm{i}}=\Delta f_{\mathrm{i}} / f_{\mathrm{i}, \mathrm{o}}$ - относительное приращение $i$-го фактора.

Произведение показателей степени является индикатором, характеризующим вклад каждого фактора в величину j-го свойства на $k$-ом шаге. Возможны следующие три варианта:

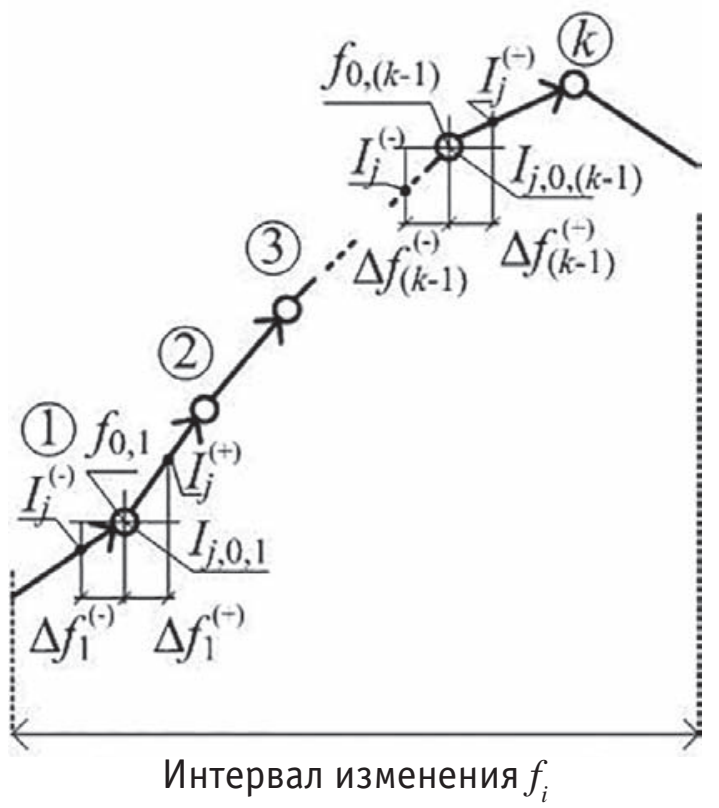

Рис. 1. Графическая интерпретация метода последовательных смещений и варьирования: 1, 2, 3...k- точки смещения (щаг); $\Delta f^{( \pm)}$- изменение (варьирование) управляющего фактора; $I^{( \pm)}$- значение j-го свойства; знаки «+» и «-» указывают на увеличение или уменьшение величины і-го управляющего фактора, соответственно; $I_{\text {о, }}$-значение j-го свойства в к-ом шаге 
- при $s_{j, k}^{( \pm)}=n_{1}^{( \pm)} \times n_{2}^{( \pm)} \times n_{3}^{( \pm)} \times \ldots \times n_{m}^{( \pm)}=\prod_{i=1}^{m} n_{i}^{( \pm)}>0$ - вклад положительный. Это указывает на возможность продолжения поиска синергетического эффекта;

- при $s_{j, k}^{( \pm)}=0$ - вклад не идентифицируется. В выбранных управляющих факторах имеются факторы, не оказывающие влияние на структурно-чувствительные свойства материала (по крайней мере, в рассмотренном диапазоне их варьирования);

- при $s_{j, k}^{( \pm)}<0$ - вклад отрицательный, что указывает на неправильный выбор управляющих факторов или неверный выбор диапазонов их варьирования. Исключением является случай достижения экстремального значения свойства. При этом отрицательное значение имеет только одно из произведений: $s_{j, k}^{(-)}$или $s_{j, k}^{(+)}$. После достижения экстремального значения свойства $s_{j, k}^{( \pm)}<0$ и дальнейший расчёт можно не проводить.

При $s_{j, k}^{( \pm)}=0$ необходимо продолжить варьирование величины факторов (дополнительные один или два шага). Если дополнительное варьирование величины факторов не приводит к изменению $s_{j, k}^{( \pm)}$, то необходимо пересмотреть перечень выбранных факторов и исключить факторы, не оказывающие влияние на структурообразование материала. При $s_{j, k}^{( \pm)}<0$ необходимо исключить факторы, оказывающие антагонистическое влияние на структурно-чувствительные свойства.

Для условия $s_{j, k}^{( \pm)}>0$ на $k$-ом шаге рассчитывается относительное изменение:

$$
S Q_{j, k}=\frac{s_{j, k}^{(+)}}{s_{j, k}^{(-)}}
$$

После проведения расчёта по всем шагам смещения осуществляется сопоставление значений $S Q_{j, k}$ и определяется шаг $k=k^{*}$, при котором

При условии

$$
S Q_{j, k^{*}}=\max
$$

$$
S Q_{j, k^{*}}>1
$$

такое скачкообразное изменение можно охарактеризовать как синергетический эффект.

При шаге $k=k_{\text {o }}$ возникают условия (на рисунке 1 соответствует точке «k»)

$$
\text { и } \begin{aligned}
& s_{j, k_{0}}^{(-)}>0 \\
& s_{j, k_{0}}^{(+)}<0,
\end{aligned}
$$

указывающие на достижение максимального значения $j$-го свойства. При этом относительное значение всегда равно:

$$
S Q_{j, k_{0}}<0 .
$$

Из представленного следует предположение о том, что значения $k^{*}$ и $k_{\text {o }}$ могут отличаться. Это имеет естественное физическое объяснение. Возникновение системы, сопровождающееся формированием взаимно-усиливающих структурных связей, приводит к нелинейному (скачкообразному) изменению её свойств. Такое взаимное усиление структурных связей фиксируется как синергетический эффект $\left(\right.$ при $\left.k=k^{*}\right)$. Дальнейшее повышение плотности и качества (например, прочности) структурных связей приводит к повышению свойств системы. Максимальные значения плотности и качества структурных связей определяют экстремальные свойства материала, которые достигаются при $k^{*}=k_{\text {o }}$. Снижение свойств системы возникает как при снижении плотности структурных связей или их качества, так и при одновременном изменении этих величин.

Важно отметить, что синергетический эффект может оказывать как положительное, так и отрицательное влияние на структурообразование материала: положительным является влияние, наблюдаемое при $k^{*}<k_{0^{\prime}}$ а отрицательное (антагонистическое) влияние будет наблюдаться при $k^{*}>k_{0}$.

Аналогичные расчеты производятся для всех свойств материала, определяющих его качество. Часть свойств, для которых будет установлено отсутствие влияния выделенных управляющих факторов во всем диапазоне их изменения, могут быть отнесены к экстенсивным свойствам, а другая часть - к интенсивным или структурно-чувствительным свойствам, то есть к свойствам, значительно зависящим от параметров структуры материала. Для каждого структурночувствительного свойства устанавливаются значения $k_{j}=k_{j}^{*}$ $n k_{j}=k_{\text {o,j }}$. Проводится классификация и устанавливается доля свойств, для которых значения $k^{*}$ и $k_{\text {о }}$ совпадают. Из закона створа И.А. Рыбьева [88] следует, что доля свойств, для ко-

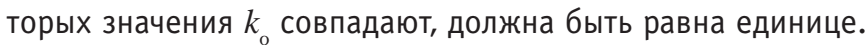
Предлагаемый алгоритм позволит сформировать дополнительную базу данных для новых строительных композитов по подтверждению указанного закона или его корректировке с учётом новых технологических решений.

После завершения процедуры определения значений управляющих факторов, при которых наблюдаются синергетический эффект и экстремальные значения свойств, проводятся исследования процессов структурообразования и параметров структуры материала.

Представленный подход дополняет метод математического планирования эксперимента, который рационально использовать для выявления перспективных областей факторного пространства факторов для проведения подробных исследований и установления синергетического эффекта, параметров структуры и особенностей структурообразования материала.

Рассмотрим пример определения синергетического эффекта и оптимальной рецептуры на модельной системе.

\section{Пример.}

Определить рецептуру комплексной модифицирующей добавки, установить рецептуру, при которой наблюдается синергетический эффект, а также оптимальный состав добавки. Комплексная добавка содержит (без физико-химического обоснования выбора) следующие компоненты: микрокремнезём, пластификатор и первичный наноразмерный материал (углеродные нанотрубки). Диапазоны изменения содержания указанных компонентов комплексной добавки (от массы минерального вяжущего) следующие: 
- микрокремнезём (фактор $\left.f_{1}\right)-5 \ldots 15 \%$;

- пластификатор (фактор $f_{2}$ ) - 0,4...0,9\%;

- углеродные нанотрубки (фактор $\left.f_{3}\right)$ - (1...6) $10^{-4} \%$.

Относительное приращение факторов на всех этапах смещения (шаг) составляет $10 \%$.

Полученные экспериментальные данные представлены на рисунках 2 и 3.

Расчёт синергетического эффекта и оптимальной рецептуры комплексной добавки проводят следующим образом. Для каждого шага смещения формируют $2 N_{f}+1$ составов (здесь $N_{f}$ - количество факторов; $N_{f}=3$ ) и определяют значение соответствующего свойства (прочности или общей пористости). Затем по формуле (6) рассчитывают значения показателей степени $n_{i, k}^{( \pm)}$и по ним их произведения $s_{j, k}^{( \pm)}$. Далее по формуле (7) производят расчет $S Q_{j, k}$. Представленный алгоритм приведён в таблице 1.

После проведения расчётов для всех шагов смещения проводится определение максимальных значений и значений соответствующих шагов $k^{*}$ и $k_{\text {о }}$ [условия (9) и (10), соот-

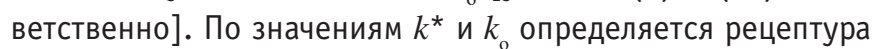
добавки, при которой возникает синергетический эффект и экстремальное значение соответствующего свойства.

Для данных на рисунках 2 и 3 значения представлены в таблицах 2 и 3.

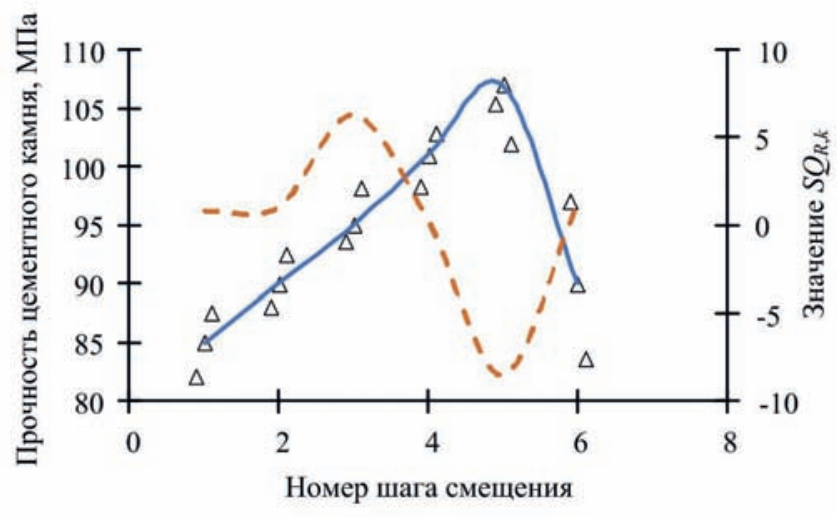

— Прочность ЦК - - $S Q_{R, k}$

Рис. 2. Изменение прочности цементного камня в зависимости от варьирования факторов

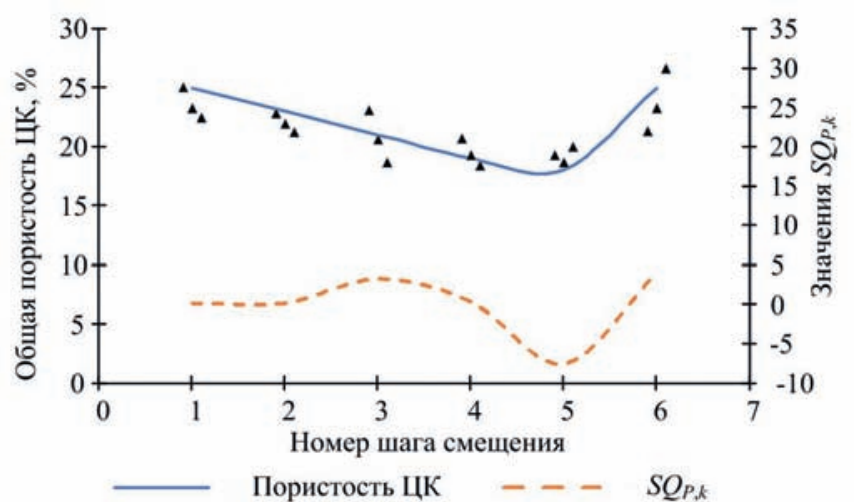

Рис. 3. Изменение общей пористости цементного камня в зависимости от варьирования факторов
Из анализа таблиц 2 и 3 следует, что синергетический эффект наблюдается при $k^{*}=3$ (положительное влияние; определение антагонистического влияния не проводилось), а экстремальные значения свойств - при $k_{o}=5$. Соответствующие графики изменение $S Q_{k}$ представлены на рисунках 2 и 3. Составы добавки для указанных условий представлены в таблице 4.

Из представленных данных видно, что для рассмотренных свойств значение $k_{0}$ является единственным, что указывает на соответствие выбранной комплексной добавки закону створа.

Далее для представленных составов необходимо провести анализ процесса структурообразования и установления параметров структуры, обеспечивающих проявление выделенных эффектов.

\section{Заключение}

Из представленного анализа следует:

1) строительное материаловедение, развитие которого базируется на новых знаниях фундаментальных и смежных прикладных наук, направлено на разработку новых технологических решений, обеспечивающих повышение эксплуатационных свойств или расширение областей применения строительных материалов. Получение новых знаний в этой научной дисциплине основано на установлении особенностей механизмов структурообразования материалов с учетом изменчивости характеристик их компонентов ${ }^{7}$;

2) расширены системные представления о строительных материалах. Такие композиты являются сложными техниче-

7 Это может составлять научную новизну и теоретическую значимость (в зависимости от уровня корректировки имеющихся теоретических представлений) диссертационной работы.

Таблица 1. Алгоритм расчёта синергетического эффекта и оптимальной рецептуры для $\boldsymbol{k}$-го шага смещения

\begin{tabular}{|c|c|c|c|c|c|}
\hline № & Состав & $\begin{array}{c}\text { Свойство } \\
I_{j, k}\end{array}$ & $\begin{array}{c}\text { Показатель } \\
\text { степени } n_{j, k}^{( \pm)}\end{array}$ & $\begin{array}{c}\text { Произведение } \\
s_{j, k}^{( \pm)}\end{array}$ & $S Q_{j, k}$ \\
\hline 1 & $f_{0,1}+f_{0,2}+f_{0,3}$ & $I_{0}$ & - & - & - \\
\hline 2 & $f_{1}^{(-)}+f_{0,2}+f_{0,3}$ & $I_{1}^{(-)}$ & $n_{1}^{(-)}$ & \multirow{3}{*}{$s_{j}^{(-)}$} & \multirow{6}{*}{$S Q_{j}$} \\
\hline 3 & $f_{0,1}+f_{2}^{(-)}+f_{0,3}$ & $I_{2}^{(-)}$ & $n_{2}^{(-)}$ & & \\
\hline 4 & $f_{0,1}+f_{0,2}+f_{3}^{(-)}$ & $I_{3}^{(-)}$ & $n_{3}^{(-)}$ & & \\
\hline 5 & $f_{1}^{(+)}+f_{0,2}+f_{0,3}$ & $I_{1}^{(+)}$ & $n_{1}^{(+)}$ & \multirow{3}{*}{$s_{j}^{(+)}$} & \\
\hline 6 & $f_{0,1}+f_{2}^{(+)}+f_{0,3}$ & $I_{2}^{(+)}$ & $n_{2}^{(+)}$ & & \\
\hline 7 & $f_{0,1}+f_{0,2}+f_{3}^{(+)}$ & $I_{3}^{(+)}$ & $n_{3}^{(+)}$ & & \\
\hline
\end{tabular}

Примечание. Значения $f^{( \pm)}{ }_{\mathrm{i}}$ рассчиитываются по формуле (3). Величину относительного изменения каждого фактора целесообразно принять величиной постоянной $\delta f_{i}=$ const.

Таблица 4. Составы комплексной добавки (\% от массы портландцемента)

\begin{tabular}{|c|l|c|c|}
\hline \multirow{2}{*}{ № } & \multirow{2}{*}{ Наименование компонента } & \multicolumn{2}{|c|}{ Установленный признак } \\
\cline { 3 - 4 } & & $\begin{array}{c}\text { Синергетический } \\
\text { эффект }\end{array}$ & $\begin{array}{c}\text { Экстремальное } \\
\text { значение }\end{array}$ \\
\hline 1 & Микрокремнезем (фактор $\left.f_{1}\right)$ & 9,0 & 13,0 \\
\hline 2 & Пластификатор (фактор $\left.f_{2}\right)$ & 0,6 & 0,8 \\
\hline 3 & Углеродные нанотрубки $\left(\right.$ фактор $f_{3}$ ) & 0,003 & 0,005 \\
\hline
\end{tabular}


Таблица 2. 0пределение синергетического эффекта по данным прочности цементного камня

\begin{tabular}{|c|c|c|c|c|c|c|c|c|c|c|c|c|}
\hline \multirow{2}{*}{ Шаг } & \multirow{2}{*}{ Фактор } & \multicolumn{3}{|c|}{ Изменение фактора $f_{i}$} & \multicolumn{3}{|c|}{ Прочность $R$, МПа } & \multirow{2}{*}{$n_{i, k}^{(-)}$} & \multirow{2}{*}{$n_{i, k}^{(+)}$} & \multirow{2}{*}{$s_{k}^{(-)}$} & \multirow{2}{*}{$s_{k}^{(+)}$} & \multirow{2}{*}{$S Q_{k}$} \\
\hline & & $f_{i, k}^{(-)}$ & $f_{0, k}$ & $f_{i, k}^{(+)}$ & $R_{i, k}^{(-)}$ & $R_{0, k}$ & $R_{i, k}^{(+)}$ & & & & & \\
\hline \multirow{3}{*}{1} & фактор $f_{1}$ & 4,5 & 5,0 & 5,5 & 82,0 & \multirow{3}{*}{85,0} & 87,0 & 0,341 & 0,244 & \multirow{3}{*}{0,011} & \multirow{3}{*}{0,009} & \multirow{3}{*}{0,820} \\
\hline & фактор $f_{2}$ & 0,36 & 0,4 & 0,44 & 80,0 & & 90,0 & 0,575 & 0,600 & & & \\
\hline & фактор $f_{3}$ & 0,0009 & 0,001 & 0,0011 & 84,5 & & 85,5 & 0,056 & 0,062 & & & \\
\hline \multirow{3}{*}{2} & фактор $f_{1}$ & 6,3 & 7,0 & 7,7 & 88,0 & \multirow{3}{*}{90,0} & 92,0 & 0,213 & 0,231 & \multirow{3}{*}{0,007} & \multirow{3}{*}{0,008} & \multirow{3}{*}{1,045} \\
\hline & фактор $f_{2}$ & 0,45 & 0,5 & 0,55 & 87,0 & & 95,0 & 0,322 & 0,567 & & & \\
\hline & фактор $f_{3}$ & 0,0018 & 0,002 & 0,0022 & 89,0 & & 90,5 & 0,106 & 0,058 & & & \\
\hline \multirow{3}{*}{3} & фактор $f_{1}$ & 8,1 & 9,0 & 9,9 & 93,0 & \multirow{3}{*}{95,0} & 100,0 & 0,202 & 0,538 & \multirow{3}{*}{0,002} & \multirow{3}{*}{0,013} & \multirow{3}{*}{6,296} \\
\hline & фактор $f_{2}$ & 0,54 & 0,6 & 0,66 & 94,0 & & 99,0 & 0,100 & 0,433 & & & \\
\hline & фактор $f_{3}$ & 0,0027 & 0,003 & 0,0033 & 94,0 & & 95,5 & 0,100 & 0,055 & & & \\
\hline \multirow{3}{*}{4} & фактор $f_{1}$ & 9,9 & 11,0 & 12,1 & 100,0 & \multirow{3}{*}{101,0} & 102,0 & 0,094 & 0,103 & \multirow{3}{*}{0,009} & \multirow{3}{*}{0,103} & \multirow{3}{*}{0,253} \\
\hline & фактор $f_{2}$ & 0,63 & 0,7 & 0,77 & 99,0 & & 101,5 & 0,190 & 0,052 & & & \\
\hline & фактор $f_{3}$ & 0,0036 & 0,004 & 0,0044 & 96,0 & & 105,0 & 0,482 & 0,408 & & & \\
\hline \multirow{3}{*}{5} & фактор $f_{1}$ & 11,7 & 13,0 & 14,3 & 105,0 & \multirow{3}{*}{107,0} & 105,0 & 0,179 & $-0,198$ & \multirow{3}{*}{0,003} & \multirow{3}{*}{$-0,024$} & \\
\hline & фактор $f_{2}$ & 0,72 & 0,8 & 0,88 & 106,0 & & 106,0 & 0,089 & $-0,099$ & & & $-8,516$ \\
\hline & фактор $f_{3}$ & 0,0045 & 0,005 & 0,0055 & 105,0 & & 95,0 & 0,179 & $-1,248$ & & & \\
\hline & фактор $f_{1}$ & 13,5 & 15,0 & 16,5 & 98,0 & & 84,0 & $-0,808$ & $-0,724$ & & & \\
\hline 6 & фактор $f_{2}$ & 0,81 & 0,9 & 0,99 & 97,0 & 90,0 & 82,0 & $-0,711$ & $-0,977$ & $-0,352$ & $-0,424$ & 1,205 \\
\hline & фактор $f_{3}$ & 0,0054 & 0,006 & 0,0066 & 96,0 & & 85,0 & $-0,613$ & $-0,600$ & & & \\
\hline
\end{tabular}

Таблица 3. Определение синергетического эффекта по данным общей пористости цементного камня

\begin{tabular}{|c|c|c|c|c|c|c|c|c|c|c|c|c|}
\hline \multirow{2}{*}{ Шаг } & \multirow{2}{*}{ Фактор } & \multicolumn{3}{|c|}{ Изменение фактора $f_{i}$} & \multicolumn{3}{|c|}{ Пористость $P, \%$} & \multirow{2}{*}{$n_{i, k}^{(-)}$} & \multirow{2}{*}{$n_{i, k}^{(+)}$} & \multirow{2}{*}{$s_{k}^{(-)}$} & \multirow[b]{2}{*}{$s_{k}^{(+)}$} & \multirow[b]{2}{*}{$S Q_{k}$} \\
\hline & & $f_{i, k}^{(-)}$ & $f_{0, k}$ & $f_{i, k}^{(+)}$ & $P_{i, k}^{(-)}$ & $P_{0, k}$ & $P_{i, k}^{(+)}$ & & & & & \\
\hline \multirow{3}{*}{1} & фактор $f_{1}$ & 4,5 & 5,0 & 5,5 & 27,0 & \multirow{3}{*}{25,0} & 24,0 & 0,730 & 0,428 & \multirow{3}{*}{0,471} & \multirow{3}{*}{0,079} & \multirow{3}{*}{0,169} \\
\hline & фактор $f_{2}$ & 0,36 & 0,4 & 0,44 & 30,0 & & 23,0 & 1,730 & 0,875 & & & \\
\hline & фактор $f_{3}$ & 0,0009 & 0,001 & 0,0011 & 26,0 & & 24,5 & 0,372 & 0,212 & & & \\
\hline \multirow{3}{*}{2} & фактор $f_{1}$ & 6,3 & 7,0 & 7,7 & 24,0 & \multirow{3}{*}{23,0} & 22,0 & 0,404 & 0,466 & \multirow{3}{*}{0,129} & \multirow{3}{*}{0,020} & \multirow{3}{*}{0,158} \\
\hline & фактор $f_{2}$ & 0,45 & 0,5 & 0,55 & 25,0 & & 21,0 & 0,791 & 0,954 & & & \\
\hline & фактор $f_{3}$ & 0,0018 & 0,002 & 0,0022 & 24,0 & & 22,9 & 0,404 & 0,046 & & & \\
\hline \multirow{3}{*}{3} & фактор $f_{1}$ & 8,1 & 9,0 & 9,9 & 22,0 & \multirow{3}{*}{21,0} & 17,0 & 0,442 & 2,217 & \multirow{3}{*}{1,168} & \multirow{3}{*}{3,765} & \multirow{3}{*}{3,224} \\
\hline & фактор $f_{2}$ & 0,54 & 0,6 & 0,66 & 23,0 & & 18,0 & 0,863 & 1,617 & & & \\
\hline & фактор $f_{3}$ & 0,0027 & 0,003 & 0,0033 & 29,0 & & 19,0 & 3,064 & 1,050 & & & \\
\hline \multirow{3}{*}{4} & фактор $f_{1}$ & 9,9 & 11,0 & 12,1 & 21,0 & \multirow{3}{*}{19,0} & 17,0 & 0,950 & 1,167 & \multirow{3}{*}{1,059} & \multirow{3}{*}{1,167} & \multirow{3}{*}{0,355} \\
\hline & фактор $f_{2}$ & 0,63 & 0,7 & 0,77 & 21,5 & & 18,0 & 1,173 & 0,567 & & & \\
\hline & фактор $f_{3}$ & 0,0036 & 0,004 & 0,0044 & 21,0 & & 18,0 & 0,950 & 0,567 & & & \\
\hline & фактор $f_{1}$ & 11,7 & 13,0 & 14,3 & 19,0 & \multirow{3}{*}{18,0} & 20,0 & 0,513 & $-1,105$ & \multirow{3}{*}{0,135} & \multirow{3}{*}{$-1,014$} & \\
\hline 5 & фактор $f_{2}$ & 0,72 & 0,8 & 0,88 & 19,0 & & 21,0 & 0,513 & $-1,617$ & & & $-7,505$ \\
\hline & фактор $f_{3}$ & 0,0045 & 0,005 & 0,0055 & 19,0 & & 19,0 & 0,513 & $-0,567$ & & & \\
\hline & фактор $f_{1}$ & 13,5 & 15,0 & 16,5 & 22,0 & & 30,0 & $-1,213$ & $-1,913$ & & & \\
\hline 6 & фактор $f_{2}$ & 0,81 & 0,9 & 0,99 & 22,0 & 25,0 & 30,0 & $-1,213$ & $-1,913$ & $-1,786$ & $-7,000$ & 3,919 \\
\hline & фактор $f_{3}$ & 0,0054 & 0,006 & 0,0066 & 22,0 & & 30,0 & $-1,213$ & $-1,913$ & & & \\
\hline
\end{tabular}


скими системами, способными к самоорганизации в неравновесных условиях. Такое понимание строительных материалов предполагает наличие синергетического эффекта (нелинейного скачкообразного изменения свойств) при влиянии управляющих факторов структурообразования. Выдвинуто предположение о существовании отличий при возникновении синергетического эффекта и экстремальных значений свойств;

3) предложен метод определения синергетического эффекта от влияния управляющих факторов на параметры структуры и свойства материала - метод «последовательных смещений и варьирования». Этот метод заключается в последовательном варьировании выделенных управляющих факторов и в установлении влияния проведённого изменения на свойства материала. Этот подход дополняет метод математического планирования эксперимента, который рационально использовать для выявления перспективных областей факторного пространства факторов, пригодных для проведения подробных исследований и установления синергетического эффекта, параметров структуры и особенностей структурообразования материала.

\section{Лuтература}

1. Анализ критического содержания наполнителя в композите с позиций теории перколяции / Бобрышев А.Н., Лахно А.В., Воронов П.В. [и др.] // Международный техникоэкономический журнал. -2013. -№ 6. -С. 93-98.

2. Соломатов, В.И. Переход «беспорядок-порядок»в структуре композиционных строительных материалов / В.И. Соломатов, А.Н. Бобрышев // Известия высших учебных заведений. Строительство и архитектура. - 1988. - № 1. - С. 47.

3. Бобрышев, А.Н. Фрактальные структуры дисперсно-наполненных композитов / А.Н. Бобрышев, А.П Прошин // Известия высшихучебных заведений. Строительство. - 1994. - № 11. - С. 65.

4. Бобрышев, А.Н. Аналитическая оценка критического содержания элементов в задачах теории протекания / А.Н. Бобрышев, Э.Р. Галимов, Н.В. Козомазов // Вестник Казанского технологического университета. - 2013. - Т. 16. - № 20. - С. 30-34.

5. Оценка кинетики фазовых переходов в твердеющих гетерогенных материалах / П.В. Воронов, А.Н. Бобрышев, А.В. Лахно [и др.] // Региональная архитектура и строительство. - 2010. - № 2. - С. 58-66.

6. Бобрышев, А.Н. Физика и синергетика дисперсно-неупорядоченных конденсированных композитных систем / А. Н. Бобрышев, В.Т. Ерофеев, В.Н. Козомазов. - СПб : Наука, 2012. -474 C.

7. Лесовик, В.С. Геоника (геомиметика). Примеры реализации в строительном материаловедении / В.С. Лесовик. - Белгород : БГТУ им. В.Г.Шухова, 2016. - 287 с.

8. Мчедлов-Петросян, О.П. Химия неорганических строительных материалов / 0.П. Мчедлов-Петросян. - М. : Стройиздат, 1971. - 224 с.

9. Системный анализ в строительном материаловедении / Ю.М. Баженов, И.А. Гарькина, А.М. Данилов, Е.В Королев - М. : МГСУ, 2012. - 432 c.
10. Данилов, А.М. Строительные материалы как системы / А.М. Данилов, Е.В. Королев, И.А. Гарькина // Строительные материалы. - 2006. - № 7. - С. 55-57.

11. Гарькина, И.А. Эволюция представлений о композиционных материалах с позиций смены парадигм / И.А. Гарькина, А.М. Данилов, Е.В. Королев // Строительные материалы. 2018. - № 1-2. - С. 60-62.

12. Данилов, А.М. Разработка строительных материалов как сложных систем / А.М. Данилов, И.А. Гарькина // Региональная архитектура и строительство. - 2016. - № 2 (27). - С. 50-54.

13. Синтез композитов: логико-методологические модели / Е.А. Будылина, И.А. Гарькина, А.М. Данилов, Д.С. Сорокин // Современные проблемы науки и образования. - 2014. № 5. - С. 149.

14. Гарькина, И.А. Системный подход к разработке материалов: модификация метода Паттерн / И.А. Гарькина, А.М. Данилов, Е.В. Королев // Вестник МГСУ. - 2011. - № 2-2. - С. 400.

15. Будылина, E.A. Формализованное описание частных критериев строительных материалов / Е.А. Будылина, И.А. Гарькина, А.М. Данилов // Региональная архитектура и строительство. - 2020. - № 1 (42). - С. 25-31.

16. Гарькина, И.А. Методы системного анализа в проектировании композитов / И.А. Гарькина, А.М. Данилов // Региональная архитектура и строительство. - 2020. - № 1 (42). - С. 63-68.

17. Управление свойствами композиционных материалов как сложных систем / В.П. Селяев, П.В. Селяев, Е.Л. Кечуткина [и др.] // Региональная архитектура и строительство. - 2019. - № 3 (40). - С. 35-43.

18. Критерий оценки энергетических свойств поверхности / М.А. Фролова, А.С. Тутыгин, А.М. Айзенштадт [и др.] // Наносистемы: физика, химия, математика. - 2011. - Т. 2. - № 4. - С. 120-125.

19. Оценка энергетического состояния сырья для получения строительных материалов / Л.А. Вешнякова, М.А. Фролова, А.М. Айзенштадт [и др.] // Строительные материалы. - 2012. - № 10. - С. 53-55.

20. Расчёт энергоёмкости горных пород как сырья для производства строительных материалов / И.Р. Абрамовская, А.М. Айзенштадт, Л.А. Вешнякова [и др.] // Промышленное и гражданское строительство. - 2012. - № 10. - С. 23-25.

21. Вешнякова, Л.А. Оценка поверхностной активности высокодисперсного сырья для композиционных строительных материалов / Л.А. Вешнякова, А.М. Айзенштадт, М.А. Фролова // Физика и химия обработки материалов. - 2015. - № 2. - С. 68-72.

22. Применение термодинамического подхода к оценке энергетического состояния поверхности дисперсных материалов / М.А. Фролова, А.С. Тутыгин, А.М. Айзенштадт [и др.] // Нанотехнологии в строительстве: научный интернет-журнал. - 2011. - Т. 3. - № 6. - С. 13-25. - Режим доступа: http:// nanobuild.ru/ru_RU/journal/Nanobuild_6_2011_RUS.pdf (дата обращения 07.08.2020). 
23. Данилов, В.E. Краевые углы смачивания набухающих порошков / В.Е. Данилов, А.М. Айзенштадт // Строительство и реконструкция. - 2020. - № 2 (88). - С. 44-50.

24. Особенности расчёта свободной энергии поверхности на основе модели межфазного взаимодействия Оунса-ВендтаРабеля-Кьельбле / В.Е. Данилов, Е.В. Королев, А.М. Айзенштадт, В.В. Строкова // Строительные материалы. - 2019. - № 11. - С. 66.

25. Лесовик, B.C. Некоторые аспекты техногенного метасоматоза в строительном материаловедении / В.С. Лесовик, Е.В. Фомина, А.М. Айзенштадт // Строительные материалы. - 2019. - № 1-2. - С. 100-106.

26. Лесовик, B.С. К проблеме техногенного метасоматоза в строительном материаловедении / В.С. Лесовик, А.А. Володченко // Вестник БГТУ им. В.Г. Шухова. - 2015. - № 4. - С. 38-41.

27. Артамонова, О.В. Концепции и основания технологий наномодифицирования структур строительных композитов. Часть 1. Общие проблемы фундаментальности, основные направления исследований и разработок / О.В. Артамонова, Е.М. Чернышов // Строительные материалы. - 2013. - № 9. - С. 82-90.

28. Чернышов, Е.М. Концепции и основания технологий наномодифицирования структур строительных композитов. Часть 2. К проблеме концептуальных моделей наномодифицирования структуры / Е.М. Чернышов, О.В. Артамонова, Г.С. Славчева // Строительные материалы. - 2014. - № 4. - С. 73-83.

29. Чернышов, E.M. Концепции и основания технологий наномодифицирования структур строительных композитов. Часть 3. Эффективное наномодифицирование систем твердения цемента и структуры цементного камня (критерии и условия) / Е.М. Чернышов, О.В. Артамонова, Г.С. Славчева // Строительные материалы. - 2015. - № 10. - С. 54-63.

30. Чернышов, E.M. Концепции и основания технологии наномодифицирования структур строительных композитов. Часть 4. Золь-гель технология нано-, микродисперсных кристаллов портландита для контактно-конденсационного компактирования структур портландитового камня и композитов на его основе / Е.М. Чернышов, Н.Д. Потамошнева, О.В. Артамонова // Строительные материалы. - 2015. - № 11. - С. 65-74.

31. Чернышов, Е.М. Концепции и основания технологий наномодифицирования структур строительных композитов. Часть 5. Эффективное микро-, наномодифицирование систем гидротермально-синтезного твердения и структуры силикатного камня (критерии и условия) / Е.М. Чернышов, В.А. Попов, О.В. Артамонова // Строительные материалы. - 2016. - № 9. - С. 38-46.

32. Артамонова, О.В. Концепции и основания технологий наномодифицирования структур строительных композитов. Часть 6. Получение наномодифицированных термально-синтезных систем твердения для конструкционной и функциональной керамики специального назначения / О.В. Артамонова // Строительные материалы. - 2017. - № 5. - С. 98.

33. Чернышов, Е.М. Концепции и основания технологий наномодифицирования структур строительных композитов. Часть 7. Заключительная: актуальное обобщение / Е.М. Чер- нышов, О.В. Артамонова // Строительные материалы. - 2019. - № 11. - С. 3-14.

34. Калашников, В.И. Супер- и гиперпластификаторы. Микрокремнеземы. Бетоны нового поколения с низким удельным расходом цемента на единицу прочности / В.И. Калашников // ALITinform: Цемент. Бетон. Сухие смеси. 2011. - № 4. - С. 60-69.

35. Параметры водопоглощения и пористости порошковоактивированного высокопрочного бетона с низким удельным расходом цемента на единицу прочности / В.Л. Хвастунов, В.И. Калашников, А.В. Хвастунов, В.В. Пауск // Региональная архитектура и строительство. - 2014. - № 4. - С. 45-51.

36. Бетоны нового поколения с низким удельным расходом цемента на единицу прочности / В.И. Калашников, С.В. Ананьев, В.Л. Хвастунов, М.Н. Мороз // Вестник центрального регионального отделения Российской академии архитектуры и строительных наук. - 2010. - № 14. - С. 27.

37. Бетоны переходного и нового поколений. Состояние и перспективы / В.И. Калашников, О.В. Тараканов, В.М. Володин [и др.] // Современные проблемы науки и образования. 2015. - № 2. - С. 151.

38. Высокоэффективные самоуплотняющиеся порошково-активированные песчаные бетоны и фибробетоны / В.И. Калашников, Володин В.М., И.В. Ерофеева, Д.А. Абрамов // Современные проблемы науки и образования. - 2015. - № 1-2. - С. 110.

39. Эффективные высокопрочные и обычные бетоны: монография / под общ. ред. В.И. Калашникова. - Пенза : Приволжский Дом знаний, 2015. - 148 с.

40. Калашников В.И. Терминология науки о бетоне нового поколения / В.И. Калашников // Строительные материалы. 2011. - № 3. - С. 103-106.

41. Изменение свойств строительных материалов при введении в них биомассы бактерий с уреазной активностью / Н.А. Степанов, Е.Н. Ефременко, Бруяко М.Г., Григорьева А.И. // Вестник МГСУ. 2017. Т. 12. № 7 (106). С. 788-796.

42. Биомодифицирование строительных материалов бактериями с уреазной активностью / М.Г. Бруяко, А.И. Григорьева, Д.С. Голотенко, А.А. Подсевалова // Строительство и реконструкция. - 2020. - № 2 (88). - С. 5-15.

43. Ерофеев, В.Т. Исследование изменений прочностных характеристик цементных композитов в зависимости от концентрации в них бактерий и возраста образцов / В.Т. Ерофеев, С.Д.С. Аль Дулайми // Приволжский научный журнал. - 2018. - № 3 (47). - С. 70-77.

44. Бактерии для получения биобетонов / В.Т. Ерофеев, С.Д.С. Аль Дулайми, В.Ф. Смирнов, В.Т. Фомичёв // БСТ: Бюллетень строительной техники. - 2018. - № 8 (1008). - С. 26-29.

45. Ерофеев, В.T. Химические аспекты процесса устранения трещин бетона с помощью бактерий [Электронный ресурс] / В.Т. Ерофеев, Д.С.Д.С. Аль, В.Т. Фомичёв // Транспортные сооружения : Интернет-журнал. - 2018. - Т. 5. - № 3. - С. 12. - Режим доступа: https://t-s.today/13SATS318.html (дата обращения 01.08.2020). 
46. Ерофеев, В.Т. Бактерии для получения самовосстанавливающихся бетонов / В.Т. Ерофеев, Д.С.Д.С. Аль, В.Ф. Смирнов // Транспортные сооружения. - 2018. - Т. 5. - № 4. - С. 7.

47. Технология самовосстановления железобетонных конструкций с помощью микроорганизмов / Ю.М. Баженов, В.Т. Ерофеев, А.Д.С.Д. Салман [и др.] // Русский инженер. 2018. - № 4 (61). - С. 46-48.

48. Строкова, В.В. Микробная карбонатная биоминерализация как инструмент природоподобных технологий в строительном материаловедении / В.В. Строкова, Д.Ю. Власов, О.В. ФранкКаменецкая // Строительные материалы. - 2019. - № 7. - С. 66-72.

49. Применение микробной карбонатной биоминерализации в биотехнологиях создания и восстановления строительных материалов: анализ состояния и перспективы развития / В.В. Строкова, Д.Ю. Власов, О.В. Франк-Каменецкая [и др.] // Строительные материалы. - 2019. - № 9. - С. 83-103.

50. Сулейманов, A.М. Актуальные задачи в прогнозировании долговечности полимерных строительных материалов / А.М. Сулейманов // Строительные материалы. - 2015. - № 5. - С. 10-13.

51. Сулейманов, А.М. Моделирование работы полимерных композиционных материалов в напряжённо-деформированном состоянии под воздействием агрессивных сред. Часть 1. Разработка методики и испытательного стенда / А.М. Сулейманов, Е.Б. Туйсина, Р.Р. Бикмухаметов // Известия Казанского государственного архитектурно-строительного университета. - 2019. - № 2 (48). - С. 239-247.

52. Туйсина, Е.Б. Моделирование работы полимерных композиционных материалов в напряжённо-деформированном состоянии под воздействием агрессивных сред. Часть 2. Метод прогнозирования долговечности полимеркомпозитной арматуры / Е.Б. Туйсина, А.М. Сулейманов // Известия Казанского государственного архитектурно-строительного университета. - 2019. - № 2 (48). - С. 255-263.

53. Гусев, Б.В. Математическая теория процессов коррозии бетона / Б.В. Гусев, А.С. Файвусович // Промышленное и гражданское строительство. - 2019. - № 7. - С. 58-63.

54. Гусев, Б.В. Математическая модель процесса атмосферной коррозии с учетом фазовых переходов бетона / Б.В. Гусев, А.С. Файвусович // Вестник Волгоградского государственного архитектурно-строительного университета. Серия: Строительство и архитектура. - 2013. - Вып. 31(50). - Ч. 2. Строительные науки. - С. 308-325.

55. Гусев, Б.В. Построение инженерной методики прогнозирования деградации железобетонных конструкций в условиях атмосферной коррозии бетона / Б.В. Гусев, А.С. Файвусович // Промышленное и гражданское строительство. - 2017. - № 10. - С. 28-38.

56. Гусев, Б.В. Математическая модель процесса сульфатной коррозии бетона с учетом физико-химических превращений бетона / Б.В. Гусев, А.С. Файвусович // Инновации и инвестиции. - 2018. - № 11. - С. 240-255.

57. Гусев, Б.В. Закономерности процессов выщелачивания бетона при фильтрации бетона / Б.В. Гусев, А.С. Файвусович,
С.И. Левадная // Промышленное и гражданское строительство. - 2013. - № 12. - С. 31-36.

58. Гусев, Б.В. Математическая теория коррозии бетона и железобетона бетона / Б.В. Гусев, А.С. Файвусович // Технология бетонов. - 2014. - № 10. - С. 35-39.

59. Гусев, Б.В. Прогнозирование долговечности бетона при выщелачивании бетона / Б.В. Гусев, А.С. Файвусович. - М. : Научный мир, 2014. - 112 с.

60. Гусев, Б.В. Построение математической теории процессов коррозии бетона / Б.В. Гусев, А.С. Файвусович // Строительные материалы. - 2008. - № 3. - С. 38-41.

61. Гусев, Б.В. Физико-математическая модель кинетики щелоче-кремнеземистой реакции в бетоне бетона / Б.В. Гусев, А.С. Файвусович // Инновации и инвестиции. - 2017. - № 8. - С. 141-149.

62. Явления массопереноса в системе «цементный раствор-композитная пластиковая арматура» на стадии структурообразования композита. Часть 1. физические представления и математическая постановка задачи / С.В. Федосов, В.Е. Румянцева, В.С. Коновалова, И.Н. Гоглев // Academia. Архитектура и строительство. - 2020. - № 1. - С. 118-123.

63. Математическое моделирование кольматации пор бетона при коррозии / С.В. Федосов, В.Е. Румянцева, И.В. Красильников [и др.] // Инженерно-строительный журнал. - 2018. - № 7 (83). - С. 198-207.

64. Основы математического моделирования биокоррозии полимербетонов / В.Т. Ерофеев, А.П. Федорцов, А.Д. Богатов, В.А. Федорцов // Фундаментальные исследования. - 2014. № 12-4. - С. 701-707.

65. Биокоррозия цементных бетонов, особенности её развития, оценки и прогнозирования / В.Т. Ерофеев, А.П. Федорцов, А.Д. Богатов, В.А. Федорцов // Фундаментальные исследования. - 2014. - № 12. - С. 708-716.

66. Теоретические и экспериментальные исследования процессов коррозии первого вида цементных бетонов при наличии внутреннего источника массы / С.В. Федосов, В.Е. Румянцева, И.В. Красильников, Н.С. Касьяненко // Строительные материалы. - 2013. - № 6. - С. 44-47.

67. Соломатов, В.И. Химическое сопротивление композиционных строительных материалов / В.И. Соломатов, В.П. Селяев. - М. : Стройиздат, 1987. - 264 с.

68. Селяев, В.П. Химическое сопротивление наполненных цементных композитов / В.П. Селяев, В.И. Соломатов, Л.М. Ошкина. - Саранск : МГУ им. Н.П. Огарева, 2001. - 150 с.

69. Селяев, В.П. Прогнозирование ресурса железобетонных изгибаемых элементов, работающих в агрессивной среде, по первой стадии предельных состояний / В.П. Селяев, В.М. Бондаренко, П.В. Селяев // Региональная архитектура и строительство. - 2017. - № 2 (31). - С. 14-24.В.П.

70. Влияние обработки сырьевых материалов низкотемпературной неравновесной плазмой на свойства строительных растворов / М.Г. Бруяко, Д.В. Кравцова, В.В. Юрченко [и др.] // Строительные материалы. - 2014. - № 12. - С. 68-71. 
71. Влияние плазмохимической обработки воды затворения на свойства строительных растворов / М.Г. Бруяко, Д.В. Кравцова, В.В. Юрченко, В.А. Ушков // Промышленное и гражданское строительство. - 2014. - № 4. - С. 45-47.

72. Ибрагимов, Р.А. Эффективность измельчения кварцевого песка в аппарате вихревого слоя / Р.А. Ибрагимов // Ресурсоэнергоэффективные технологии в строительном комплексе региона. - 2019. - № 11. - С. 213-216.

73. Оптимальные параметры и картина магнитного поля рабочей камеры в аппаратах с вихревым слоем / Р.А. Ибрагимов, Е.В. Королев, Р.Я. Дебердеев, В.В. Лексин // Строительные материалы. - 2018. - № 7. - С. 64-67.

74. Эффективность активации минеральных вяжущих в аппаратах вихревого слоя / Р.А. Ибрагимов, Е.В Королев, Р.А. Каюмов [и др.] // Инженерно-строительный журнал. - 2018. - № 6 (82). - С. 191-198.

75. Прочность тяжёлого бетона на портландцементе, обработанном в аппарате вихревого слоя / Р.А. Ибрагимов, Е.В. Королев, Т.Р. Дебердеев, В.В. Лексин // Строительные материалы. - 2017. - № 10. - С. 28-31.

76. Возможности предсказания коэффициента термического расширения материалов на основе поливинилхлорида / А.А. Аскадский, С. Ван, Е.А. Курская [и др.] // Строительные материалы. - 2019. - № 11. - С. 57-65.

77. Аскадский, А.А. Расчётная схема для оценки реологических свойств полимеров и их смесей / А.А. Аскадский, Т.А. Мацеевич, В.И. Кондращенко // Строительные материалы. 2018. - № 10. - С. 64-68.

78. Статистическое моделирование как метод выявления коррозии цементных композитов / А.Н. Гришина, А.Н. Земляков, Е.В. Королев [и др.] // Вестник МГСУ. - 2014. - № 4. - С. 87-97.

79. Смирнов, В.А. Моделирование и инструментальные средства численного анализа в нанотехнологии материаловедения: обзор [Электронный ресурс] / В.А. Смирнов, Е.В. Королев, А.В. Евстигнеев // Нанотехнологии в строительстве : научный интернет-журнал. - 2014. - Т. 6. - № 5. - С. 34-47. - Режим доступа: http://nanobuild.ru/ru_RU/journal/ Nanobuild-5-2014/34-47.pdf (дата обращения 01.08.2020).

80. Смирнов, В.А. Стохастическое моделирование наноразмерных систем [Электронный ресурс] / В.А. Смирнов, Е.В. Королев, С.С. Иноземцев // Нанотехнологии в строительстве: научный интернет-журнал. - 2012. - Т. 4. - № 1. - С. 6-14. - Режим доступа: http://nanobuild.ru/ru_RU/journal/ Nanobuild_1_2012_RUS.pdf (дата обращения 03.08.2020).

81. Королев, E.В. Динамическое моделирование наноразмерных систем [Электронный ресурс] / Е.В. Королев, В.А. Смирнов, А.С. Иноземцев // Нанотехнологии в строительстве: научный интернет-журнал. - 2012. - Т. 4. - № 3. - С. 26-34. - Режим доступа: http://nanobuild.ru/ru_RU/journal/ Nanobuild_3_2012_RUS.pdf (дата обращения 31.07.2020).

82. Смирнов, В.А. Иерархическое моделирование строительных материалов как дисперсных систем: специализиро- ванная программная реализация / В.А. Смирнов, Е.В Королев // Строительные материалы. - 2019. - № 1-2. - С. 43-53.

83. Кондращенко, В.И. Применение методов компьютерного материаловедения в биотехнологических исследованиях / В.И. Кондращенко // Строительные материалы. - 2006. - № 3. - С. 76.

84. Воробьев, B.A. Основные задачи компьютерного материаловедения строительных композитов / В.А. Воробьев, А.В. Илюхин // Строительные материалы. - 2006. - № 7. - С. 19-21.

85. Возможности и перспективы компьютерного моделирования строительных композитных материалов / В.А. Воробьев, Ю.Э. Васильев, В.И. Марсов, Е.И. Бокарев // Промышленное и гражданское строительство. - 2012. - № 3. - С. 62-63.

86. Королев, Е.В. Технико-экономическая эффективность новых технологических решений. Анализ и совершенствование / Е.В. Королев // Строительные материалы. - 2017. - № 3. - С. 85-89.

87. Шаповалов, В.И. Моделирование синергетических систем. Метод пропорций и другие математические методы / В.И. Шаповалов - М. : Проспект, 2016. - 136 с.

88. Рыбьев, И.А. Строительное материаловедение / И.А. Рыбьев. - М. : Высшая школа, 2004. - 701 с.

\section{References}

1. Bobryshev A.N., Lahno A.V., Voronov P.V., Bobryshev A.A., Novikov E.V. Analiz kriticheskogo soderzhaniya napolnitelya $v$ kompozite s pozitsii teorii perkolyatsii [Analysis of the critical content of the filler in the composite from the standpoint of the theory of percolation]. In: Mezhdunarodnyj tehnikojekonomicheskij zhurnal [The International Technical-Economic Journal], 2013. no. 6, pp. 93-98. (In Russ.)

2. Solomatov V.I., Bobryshev A.N. Perekhod «besporyadokporyadok» v strukture kompozitsionnykh stroitel'nykh materialov [The transition "disorder-order" in the structure of composite building materials]. In: Izvestija vysshih uchebnyh zavedenij. Stroitel'stvo i arhitektura [Proceedings of higher educational institutions. Construction and architecture ], 1988, no. 1, pp. 47. (In Russ.)

3. Bobryshev A.N., Proshin A.P. Fraktal'nye struktury dispersno-napolnennykh kompozitov [Fractal structures of dispersed-filled composites]. In: Izvestija vysshih uchebnyh zavedenij. Stroitel'stvo [Proceedings of higher educational institutions. Construction], 1994, no. 11, pp. 65. (In Russ.)

4. Bobryshev A.N., GalimovJe.R., Kozomazov N.V. Analiticheskaya otsenka kriticheskogo soderzhaniya elementov $v$ zadachakh teorii protekaniya [Analytical assessment of the critical content of elements in the problems of percolation theory]. In: Vestnik Kazanskogo tehnologicheskogo universiteta [Kazan Technological University Bulletin], 2013, Vol. 16, no. 20, pp. 30-34. (In Russ)

5. Voronov P.V., Bobryshev A.N., Lahno A.V., Kuvshinov P.I., Tumanova N.N. Otsenka kinetiki fazovykh perekhodov $v$ tverdeyushchikh geterogennykh materialakh [Assessment of the kinetics of phase transitions in hardening heterogeneous materials]. In: Regional'naja arhitektura i stroitel'stvo. [Regional Architecture and Engineering], 2010, no. 2, pp. 58-66. (In Russ.) 
6. Bobryshev A.N., Erofeev V.T., Kozomazov V.N. Fizika i sinergetika dispersno-neuporjadochennyh kondensirovannyh kompozitnyh system [Physics and synergetics of disperseddisordered condensed composite systems]. St.-Petersburg, Nauka Publ., 2012, 474 p. (In Russian).

7. Lesovik V.S. Geonika (geomimetika). Primery realizacii v stroitel'nom materialovedenii [Geonics (geomimetics). Examples of implementation in building materials science]. Belgorod, BGTU named V.G.Shuhova Publ., 2016, 287 p. (In Russ.)

8. Mchedlov-Petrosjan 0.P. Himija neorganicheskih stroitel'nyh materialov [Chemistry of inorganic building materials]. Moscow, Strojizdat Publ., 1971, 224 p. (In Russ.)

9. Bazhenov Ju.M., Gar'kina I.A., Danilov A.M., Korolev E.V. Sistemnyj analiz v stroitel'nom materialovedenii [System analysis in construction materials science]. Moscow, MGSU Publ., 2012, 432 p. (In Russ.)

10. Danilov A.M., Korolev E.V., Gar'kina I.A. Stroitel'nye materialy kak sistemy [Building materials as systems]. In: Stroitel'nye materialy, 2006, no. 7, pp. 55-57. (In Russ.)

11. Gar'kina I.A., Danilov A.M., Korolev E.V. Evolyutsiya predstavlenii o kompozitsionnykh ma-terialakh s pozitsii smeny paradigm [Evolution of ideas about composite materials from the standpoint of changing paradigms]. In: Stroitel'nye materialy, 2018, no. 1-2, pp. 60-62. (In Russ.)

12. Danilov A.M., Gar'kina I.A. Razrabotka stroitel'nykh materialov kak slozhnykh sistem [Development of building materials as complex systems]. In: Regional'naja arhitektura $i$ stroitel'stvo [Regional Architecture and Engineering], 2016, no. 2 (27), pp. 50-54. (In Russ)

13. Budylina E.A., Gar'kina I.A., Danilov A.M., Sorokin D.S. Sintez kompozitov:logiko-metodologicheskie modeli [Synthesis of composites: logical and methodological models]. In: Sovremennye problemy nauki i obrazovanija [Modern problems of science and education], 2014, no. 5, p. 149. (In Russ.)

14. Gar'kina I.A., Danilov A.M., Korolev E.V. Sistemnyi podkhod k razrabotke materialov: modifikatsiya metoda Pattern [A systematic approach to the development of materials: modification of the Pattern method]. In: Vestnik MGSU, 2011, no. 2-2, p. 400. (In Russ., abstr. in Engl.)

15. Budylina E.A., Gar'kina I.A., Danilov A.M. Formalizovannoe opisanie chastnykh kriteriev stroitel'nykh materialov [Formalized description of private criteria for building materials]. In: Regional'naja arhitektura i stroitel'stvo [Regional Architecture and Engineering], 2020, no. 1 (42), pp. 25-31. (In Russ., abstr. in Engl.)

16. Gar'kina I.A., Danilov A.M. Metody sistemnogo analiza $\checkmark$ pro-ektirovanii kompozitov [Methods of system analysis in the design of composites]. In: Regional'naja arhitektura $i$ stroitel'stvo [Regional Architecture and Engineering], 2020, no. 1 (42), pp. 63-68. (In Russ., abstr. in Engl.)

17. Seljaev V.P., Seljaev P.V., Kechutkina E.L., Danilov A.M., Gar'kina I.A. Upravlenie svoistvami kompozitsionnykh materialov kak slozhnykh system [Management of the properties of composite materials as complex systems]. In: Regional'naja arhitektura i stroitel'stvo [Regional Architecture and Engineering], 2019, no. 3 (40), pp. 35-43. (In Russ., abstr. in Engl.)

18. Frolova M.A., Tutygin A.S., Ajzenshtadt A.M., Lesovik V.S., Mahova T.A., Pospelova T.A. Kriterii otsenki energeticheskikh svoistv poverkhnosti [A criterion for evaluating the energy properties of a surface]. In: Nanosistemy: fizika, himija, matematika [Nanosystems: Physics, Chemistry, Mathematics]. 2011. Vol. 2. no. 4, pp. 120-125. (In Russ.)

19. Veshnjakova L.A., Frolova M.A., AjzenshtadtA.M., Lesovik V.S., Mihajlova 0.N., Mahova T.A. Otsenka energeticheskogo sostoyaniya syr'ya dlya polucheniya stroi-tel'nykh materialov [Assessment of the energy state of raw materials for obtaining building materials]. In: Stroitel'nye materialy, 2012, no. 10, pp. 53-55. (In Russ.)

20. Abramovskaya I.R., Aizenshtadt A.M., Veshnyakova L.A., Frolova M.A., Lesovik V.S., Kazlitin S.A. Raschet energoemkosti gornykh porod kak syr'ya dlya proizvodstva stroitel'nykh materialov [Calculation of energy consumption of rocks as raw materials for the production of building materials] In: Promyshlennoe i grazhdanskoe stroitel'stvo [Industrial and Civil Engineering], 2012, no. 10, pp. 23-25. (In Russ., abstr. in Engl.)

21. Veshnyakova L.A., Aizenshtadt A.M., Frolova M.A. Otsenka poverkhnostnoi aktivnosti vysokodispersnogo syr'ya dlya kompozitsionnykh stroitel'nykh materialov [Assessment of surface activity of highly dispersed raw materials for composite building materials]. In: Fizika i khimiya obrabotki materialov [Physics and Chemistry of Materials Treatment], 2015, no. 2, pp. 68-72. (In Russ., abstr. in Engl.)

22. Frolova M.A., Tutygin A.S., Aizenshtadt A.M., Makhova T.A., Pospelova T.A. Primenenie termodinamicheskogo podkhoda k otsenke energetiche-skogo sostoyaniya poverkhnosti dispersnykh materialov [Application of the thermodynamic approach to the assessment of the energy state of the surface of dispersed materials]. In: Nanotekhnologii $v$ stroitel'stve: nauchnyi internet-zhurnal [Nanobuild.ru], 2011, Vol. 3, no. 6, pp. 13-25. Access mode: http://nanobuild.ru/ru_RU/journal/ Nanobuild_6_2011_RUS.pdf (accessed 07.08.2020).

23. Danilov V.E., Aizenshtadt A.M. Kraevye ugly smachivaniya nabukhayushchikh poroshkov [Contact angles of wetting of swelling powders]. In: Stroitel'stvo i rekonstruktsiya [Building and Reconstruction], 2020, no. 2 (88), pp. 44-50. (In Russ., abstr. in Engl.)

24. Danilov V.E., Korolev E.V., Aizenshtadt A.M., Strokova V.V. Osobennosti rascheta svobodnoi energii poverkhnosti na osnove modeli mezhfaznogo vzaimodeistviya Ounsa-VendtaRabelya-K'el'ble [Features of the calculation of the surface free energy on he basis of the Ouns-Wendt-Rabel-Kjelble interphase interaction mode]. In: Stroitel'nye materialy, 2019, no. 11, pp. 66. (In Russ., abstr. in Engl.)

25. Lesovik V.S., Fomina E.V., Aizenshtadt A.M. Nekotorye aspekty tekhnogennogo metasomatoza $\vee$ stroitel'nom materialovedenii [Some aspects of technogenic metasomatism in construction materials science]. In: Stroitel'nye materialy, 2019, no. 1-2, pp. 100-106. (In Russ., abstr. in Engl.) 
26. Lesovik V.S., Volodchenko A.A. K probleme tekhnogennogo metasomatoza v stroitel'nom materialovedenii [To the problem of technogenic metasomatism in construction materials science]. In: Vestnik BGTU im. V.G. Shukhova [Bulletin of BSTU named after V.G. Shukhov], 2015, no. 4, pp. 38-41. (In Russ., abstr. in Engl.)

27. Artamonova 0.V., Chernyshov E.M. Kontseptsii i osnovaniya tekhnologii nanomodifitsirovaniya struktur stroitel'nykh kompozitov. Chast' 1. Obshchie problemy fundamental'nosti, osnovnye napravleniya issledovanii i razrabotok [Concepts and foundations of technologies for nanomodification of structures of building composites. Part 1. General problems of fundamentality, main directions of research and development]. In: Stroitel'nye materialy, 2013, no. 9, pp. 82-90. (In Russ., abstr. in Engl.)

28. Chernyshov E.M., Artamonova 0.V., Slavcheva G.S. Kontseptsii i osnovaniya tekhnologii nanomodifitsirovaniya struktur stroitel'nykh kompozitov. Chast' 2. K probleme kontseptual'nykh modelei nanomodifitsirovaniya struktury [Concepts and foundations of technologies for nanomodification of structures of building composites. Part 2. On the problem of conceptual models of nanomodification of the structure]. In: Stroitel'nye materialy, 2014, no. 4, pp. 73-83. (In Russ., abstr. in Engl.)

29. Chernyshov E.M., Artamonova O.V., Slavcheva G.S. Kontseptsii i osnovaniya tekhnologii nanomodifitsirovaniya struktur stroitel'nykh kompozitov. Chast' 3. Effektivnoe nanomodifitsirovanie sistem tverdeniya tsementa i struktury tsementnogo kamnya (kriterii i usloviya) [Concepts and foundations of technologies for nanomodification of building composites structures. Part 3. Effective nanomodification of cement hardening systems and cement stone structure (criteria and conditions)]. In: Stroitel'nye materialy, 2015, no. 10, pp. 54-63. (In Russ., abstr. in Engl.)

30. Chernyshov E.M., Potamoshneva N.D., Artamonova 0.V. Kontseptsii i osnovaniya tekhnologii nanomodi-fitsirovaniya struktur stroitel'nykh kompozitov. Chast' 4. Zol'-gel' tekhnologiya nano-, mikrodispersnykh kristallov portlandita dlya kontaktno-kondensatsionnogo kompaktirovaniya struktur portlanditovogo kamnya i kompozitov na ego osnove [Concepts and foundations of technology for nanomodification of structures of building composites. Part 4. Sol-gel technology of nano-, microdispersed crystals of portlandite for contactcondensation compaction of structures of portlandite stone and composites based on it]. In: Stroitel'nye materialy, 2015, no. 11, pp. 65-74. (In Russ., abstr. in Engl.)

31. Chernyshov E.M., Popov V.A., Artamonova 0.V. Contseptsii i osnovaniya tekhnologii nanomodifitsirovaniya struktur stroitel'nykh kompozitov. Chast' 5. Effektivnoe mikro-, nanomodifitsirovanie sistem gidrotermal'no-sinteznogo tverdeniya i struktury silikatnogo kamnya (kriterii i usloviya) [Concepts and foundations of technologies for nanomodification of building composites structures. Part 5. Effective micro-, nanomodification of systems of hydrothermal-synthesis hardening and structure of silicate stone (criteria and conditions)]. In: Stroitel'nye materialy, 2016, no. 9, pp. 38-46. (In Russ., abstr. in Engl.).

32. Artamonova 0.V. Kontseptsii i osnovaniya tekhnologii nanomodi-fitsirovaniya struktur stroitel'nykh kompozitov. Chast' 6. Poluchenie nano-modifitsirovannykh termal'no-sinteznykh sistem tverdeniya dlya konstruktsionnoi i funktsional'noi keramiki spetsial'nogo naznacheniya [Concepts and foundations of technologies for nanomodification of building composites structures. Part 6 . Obtaining nanomodified thermal-synthesis hardening systems for structural and functional ceramics for special purposes]. In: Stroitel'nye materialy, 2017, no. 5, p. 98. (In Russ., abstr. in Engl.)

33. Chernyshov E.M., Artamonova 0.V. Kontseptsii i osnovaniya tekhnologii nanomodi-fitsirovaniya struktur stroitel'nykh kompozitov. Chast' 7. Zaklyuchitel'naya: aktual'noe obobshchenie [Concepts and foundations of technologies for nanomodification of building composites structures. Part 7. Final: topical generalization]. In: Stroitel'nye materialy, 2019, no. 11, pp. 3-14. (In Russ., abstr. in Engl.)

34. Kalashnikov V.I. Super- i giperplastifikatory. mikrokremnezemy. Betony novogo pokoleniya s nizkim udel'nym raskhodom tsementa na edinitsu prochnosti [Super- and hyperplasticizers. Microsilica. New generation concretes with low specific cement rush per unit of strength]. In: ALITinform: Cement. Beton. Suhie smesi, 2011, no. 4, pp. 60-69. (In Russ)

35. Hvastunov V.L., Kalashnikov V.I., Hvastunov A.V., Pausk V.V. Parametry vodopogloshcheniya i poristosti poroshkovoaktivirovannogo vysokoprochnogo betona s nizkim udel'nym raskhodom tse-menta na edinitsu prochnosti [Parameters of water absorption and porosity of powder-activated high-strength concrete withlow specific cement rush per unit of strength]. In: Regional'naja arhitektura i stroitel'stvo [Regional Architecture and Engineering], 2014. no. 4, pp. 45-51. (In Russ., abstr. in Engl.)

36. Kalashnikov V.I., Anan'ev S.V., Hvastunov V.L., Moroz M.N. Betony novogo pokoleniya s nizkim udel'nym raskhodom tsementa na edinitsu prochnosti [New generation concretes withlow specific cement rush per unit of strength]. In: Vestnik central'nogo regional'nogo otdelenija Rossijskoj akademii arhitektury $i$ stroitel'nyh nauk [Bulletin of the Central Regional Branch of the Russian Academy of Architecture and Construction Sciences], 2010, no. 14, p. 27. (In Russ.)

37. Kalashnikov V.I., Tarakanov 0.V., Volodin V.M., Erofeeva I.V., Abramov D.A. Betony perekhodnogo i novogo pokolenii. Sostoyanie i perspektivy [Transitional and new generation concretes. State and prospects]. In: Sovremennye problemy nauki i obrazovanija [Modern problems of science and education], 2015, no. 2, pp. 151. (In Russ.)

38. Kalashnikov V.I., Volodin V.M., Erofeeva I.V., Abramov D.A. Vysokoeffektivnye samouplotnyayushchiesya poroshkovoaktivirovannye peschanye betony i fibrobetony [Highly efficient self-compacting powder-activated sand concretes and fiber concretes]. In: Sovremennye problemy nauki i obrazovanija [Modern problems of science and education], 2015, no. 1-2, pp. 110. (In Russ.)

39. V.I. Kalashnikov (ed.). Effektivnye vysokoprochnye $i$ obychnye betony [Effective high-strength and conventional 
concrete]. Penza, Privolzhsky House of Knowledge Publ., 2015, 148 p. (In Russ.)

40. Kalashnikov V.I. Terminologiya nauki o betone novogo pokoleniya [erminology of a new generation of concrete science]. In: Stroitel'nye materialy, 2011, no. 3, pp. 103-106. (In Russ., abstr. in Engl.)

41. Stepanov N.A., Efremenko E.N., Bruyako M.G., Grigor'eva A.I. Izmenenie svoistv stroitel'nykh materialov pri vvedenii v nikh biomassy bakterii s ureaznoi aktivnost'yu [Changes in the properties of building materials with the introduction of the biomass of bacteria with urease activity]. In: Vestnik MGSU, 2017, Vol. 12. no. 7 (106). S. 788-796. (In Russ., abstr. in Engl.)

42. Bruyako M.G., Grigor'eva A.I., Golotenko D.S., Podsevalova A.A. Biomodifitsirovanie stroitel'nykh materialov bakteriyami s ureaznoi aktivnost'yu [Biomodification of building materials by bacteria with urease activity ]. In: Stroitel'stvo i rekonstruktsiya [Building and Reconstruction], 2020. no. 2 (88), pp. 5-15. (In Russ., abstr. in Engl.)

43. Erofeev V.T., Al' Dulaimi S.D.S. Issledovanie izmenenii prochnostnykh kharakteristik tsementnykh kompozitov $v$ zavisimosti ot kontsentratsii v nikh bakterii i vozrasta obraztsov [Investigation of changes in the strength characteristics of cement composites depending on the concentration of bacteria in them and the age of the samples ]. In: Privolzhskii nauchnyi zhurnal [Privolzhsky Scientific Journal], 2018, no. 3 (47). pp. 70-77. (In Russ., abstr. in Engl.)

44. Erofeev V.T., Al' Dulaimi S.D.S., Smirnov V.F., Fomichev V.T. Bakterii dlya polucheniya biobetonov [Bacteria for the production of bioconcrete]. In: BST: Byulleten' stroitel'noi tekhniki, 2018, no. 8 (1008), pp. 26-29. (In Russ., abstr. in Engl.)

45. Erofeev V.T., Al' D.S.D.S., Fomichev V.T. Khimicheskie aspekty protsessa ustraneniya treshchin betona s pomoshch'yu bakterii [Chemical aspects of the process of eliminating cracks in concrete with the help of bacteria]. In: Transportnye sooruzheniya [Russian journal of transport engineering], 2018. Vol. 5, no. 3, p. 12. Access mode: https://t-s.today/13SATS318. html (accessed 08/01/2020).

46. Erofeev V.T., Al' D.S.D.S., Smirnov V.F. Bakterii dlya polucheniya samovosstanavliva-yushchikhsya betonov [Bacteria for the production of self-healing concretes]. In: Transportnye sooruzheniya [Russian journal of transport engineering], 2018. Vol. 5, no. 4, p. 7. (In Russ., abstr. in Engl.)

47. Bazhenov Yu.M., Erofeev V.T., Salman A.D.S.D., Smirnov V.F., Fomichev V.T. Tekhnologiya samovosstanovleniya zhelezobetonnykh konstruktsii s pomoshch'yu mikroorganizmov [Self-healing technology of reinforced concrete structures using microorganisms]. In: Russkii inzhener [Russian Engineer], 2018, no. 4 (61), pp. 46-48. (In Russ., abstr. in Engl.)

48. Strokova V.V., Vlasov D.Yu., Frank-Kamenetskaya O.V. Mikrobnaya karbonatnaya biomineralizatsiya, kak instrument prirodopodobnykh tekhnologii v stroitel'nom materialovedenii [Microbial carbonate biomineralization as a tool of nature-like technologies in building materials science]. In: Stroitel'nye materialy, 2019, no.7,pp. 66-72. (In Russ., abstr. in Engl.)
49. Strokova V.V., Vlasov D.Yu., Frank-Kamenetskaya O.V., Dukhanina U.N., Balitskii D.A. Primenenie mikrobnoi karbonatnoi biomineralizatsii v biotekhnologiyakh sozdaniya i vosstanovleniya stroitel'nykh materialov: analiz sostoyaniya i perspektivy razvitiya [The use of microbial carbonate biomineralization in biotechnologies for the creation and restoration of building materials: analysis of the state and development prospects]. In: Stroitel'nye materialy, 2019, no. 9, pp. 83-103. (In Russ., abstr. in Engl.)

50. Suleimanov A.M. Aktual'nye zadachi v prognozirovanii dolgovechnosti polimernykh stroitel'nykh materialov [Actual problems in predicting the durability of polymeric building materials]. In: Stroitel'nye materialy, 2015, no. 5, pp. 10-13. (In Russ., abstr. in Engl.)

51. Suleimanov A.M., Tuisina E.B., Bikmukhametov R.R. Modelirovanie raboty polimernykh kompozitsionnykh materialov $\checkmark$ napryazhenno-deformirovannom sostoyanii pod vozdeistviem agressivnykh sred. Chast' 1 . Razrabotka metodiki i ispytatel'nogo stenda [Modeling the operation of polymer composite materials in a stress-strain state under the influence of aggressive media. Part 1. Development of a methodology and test bench]. In: Izvestiya Kazanskogo gosudarstvennogo arkhitekturno-stroitel'nogo universiteta [News of the Kazan State University of Architecture and Engineering], 2019, no. 2 (48), pp. 239-247. (In Russ., abstr. in Engl.)

52. Tuisina E.B., Suleimanov A.M. Modelirovanie raboty polimernykh kompozitsionnykh materialov $\vee$ napryazhennodeformirovannom sostoyanii pod vozdeistviem agressivnykh sred. Chast' 2. Metod prognozirovaniya dolgovechnosti polimerkompozitnoi armatury [Modeling the operation of polymer composite materials in a stress-strain state under the influence of aggressive media. Part 2. Method for predicting the durability of polymer-composite reinforcement]. In: Izvestiya Kazanskogo gosudarstvennogo arkhitekturno-stroitel'nogo universiteta [News of the Kazan State University of Architecture and Engineering], 2019, no. 2 (48), pp. 255-263. (In Russ., abstr. in Engl.)

53. Gusev B.V., Faivusovich A.S. Matematicheskaya teoriya protsessov korrozii betona [Mathematical theory of concrete corrosion processes]. In: Promyshlennoe i grazhdanskoe stroitel'stvo [Industrial and Civil Engineering], 2019, no. 7, pp. 58-63. (In Russ., abstr. in Engl.)

54. Gusev B.V., Faivusovich A.S. Matematicheskaya model' protsessa atmosfernoi korrozii s uchetom fazovykh perekhodov [Mathematical model of the atmospheric corrosion process taking into account phase transitions]. In: Vestnik Volgogradskogo gosudarstvennogo arkhitekturno-stroitel'nogo universiteta. Seriya: Stroitel'stvo i arkhitektura [Bulletin of Volgograd state university of architecture and civil engineering. Series: Construction and architecture], 2013, Iss. 31 (50). P. 2. Construction sciences, pp. 308-325. (In Russ., abstr. in Engl.)

55. Gusev B.V., Faivusovich A.S. Postroenie inzhenernoi metodiki prognozirovaniya degradatsii zhelezobetonnykh konstruktsii v usloviyakh atmosfernoi korrozii [Construction of an engineering technique for predicting the degradation of reinforced concrete structures in conditions of atmospheric corrosion]. In: 
Promyshlennoe i grazhdanskoe stroitel'stvo [Industrial and Civil Engineering], 2017, no. 10, pp. 28-38. (In Russ., abstr. in Engl.)

56. Gusev B.V., Faivusovich A.S. Matematicheskaya model' protsessa sul'fatnoi korrozii betona s uchetom fiziko-khimicheskikh prevrashchenii [Mathematical model of the process of sulfate corrosion of concrete taking into account the physical and chemical transformations of concrete]. In: Innovatsii $i$ investitsii [Innovations and investments], 2018, no. 11, pp. 240-255. (In Russ.)

57. Gusev B.V., Faivusovich A.S. Levadnaya S.I. Zakonomernosti protsessov vyshchelachivaniya betona pri fil'tratsii [Regularities of concreteleaching processes during concrete filtration]. In: Promyshlennoe i grazhdanskoe stroitel'stvo [Industrial and Civil Engineering], 2013, no. 12, pp. 31-36. (In Russ., abstr. in Engl.)

58. Gusev B.V., Faivusovich A. S. Matematicheskaya teoriya korrozii betona i zhelezobetona [Mathematical theory of corrosion of concrete and reinforced concrete concrete]. In: Tekhnologiya betonov [Technology of concrete], 2014, no. 10, pp. 35-39. (In Russ., abstr. in Engl.)

59. Gusev B.V., Faivusovich A.S. Prognozirovanie dolgovechnosti betona pri vyshchelachivanii [Prediction of the durability of concrete when leaching concrete]. Moscow, Nauchnyi mir Publ., 2014, 112 p.

60. Gusev B.V., Faivusovich A.S. Postroenie matematicheskoi teorii protsessov korrozii betona [Construction of a mathematical theory of concrete corrosion processes]. In: Stroitel'nye materialy, 2008, no. 3, pp. 38-41. (In Russ., abstr. in Engl.)

61. Gusev B. V., Faivusovich A. S. Fiziko-matematicheskaya model' kinetiki shcheloche-kremnezemistoi reaktsii $v$ betone [Physico-mathematical model of the kinetics of alkali-siliceous reaction in concrete concrete]. In: Innovatsii $i$ investii [Innovations and investments], 2017, no. 8, pp. 141-149. (In Russ.)

62. Fedosov S.V., Rumyantseva V.E., Konovalova V.S., Goglev I.N. Yavleniya massoperenosa $v$ sisteme «tsementnyi rastvorkompozitnaya plastikovaya armatura» na stadii strukturoobrazovaniya kompozita. Chast' 1 . fizicheskie predstavleniya i matematicheskaya postanovka zadachi [Phenomena of mass transfer in the system "cement mortar-composite plastic reinforcement" at the stage of structure formation of the composite. Part 1. Physical representations and mathematical formulation of the problem]. In: Academia. Arkhitektura istroitel'stvo [Academy. Architecture and construction], 2020, no. 1, pp. 118-123. (In Russ., abstr. in Engl.)

63. Fedosov S.V., Rumyantseva V.E., Krasil'nikov I.V., Konovalova V.S., Evsyakov A.S. Matematicheskoe modelirovanie kol'matatsii por betona pri korrozii [Mathematical modeling of colmatation of concrete pores during corrosion]. In: Inzhenerno-stroitel'nyi zhurnal [Magazine of Civil Engineering], 2018, no. 7 (83), pp. 198-207. (In Russ., in Engl.)

64. Erofeev V.T., Fedortsov A.P., Bogatov A.D., Fedortsov V.A. Osnovy matematicheskogo modelirovaniya biokorrozii polimerbetonov [Fundamentals of mathematical modeling of biocorrosion polymer-concrete]. In: Fundamental'nye issledovaniya [Fundamental research], 2014, no. 12-4. pp. 701-707. (In Russ., abstr. in Engl.)
65. Erofeev V.T., Fedortsov A.P., Bogatov A.D., Fedortsov V.A. Biokorroziya tsementnykh betonov, osobennosti ee razvitiya, otsenki i prognozirovaniya [Fundamentals of mathematical modeling of biocorrosion polymer-concrete]. In: Fundamental'nye issledovaniya [Fundamental research], 2014, no. 12-4. pp. 708-716. (In Russ., abstr. in Engl.)

66. Fedosov S.V., Rumyantseva V.E., Krasil'nikov I.V., Kas'yanenko N.S. Teoreticheskie i eksperimental'nye issledovaniya protsessov korrozii pervogo vida tsementnykh betonov pri nalichii vnutrennego istochnika massy [Theoretical and experimental research of corrosion processes of the first type of cement concretes in the presence of an internal source of mass]. In: Stroitel'nye materialy, 2013, no. 6, pp. 44-47. (In Russ., abstr. in Engl.)

67. Solomatov V.I., Selyaev V.P. Khimicheskoe soprotivlenie kompozitsionnykh stroitel'nykh materialov [Chemical resistance of composite building materials]. Moscow, Stroiizdat Publ.,1987,264 p.

68. Selyaev V.P., Solomatov V.I., Oshkina L.M. Khimicheskoe soprotivlenie napolnennykh tsementnykh kompozitov [Chemical resistance of filled cement composites]. Saransk, MGU im. N.P. Ogareva Publ., 2001, 150 p.

69. Selyaev V.P., Bondarenko V.M., Selyaev P.V. Prognozirovanie resursa zhelezobetonnykh izgibaemykh elementov, rabotayushchikh v agressivnoi srede, po pervoi stadii predel'nykh sostoyanii [Forecasting the resource of reinforced concrete bending elements operating in an aggressive environment, according to the first stage oflimiting states]. In: Regional'naya arkhitektura istroitel'stvo [Regional Architecture and Engineering], 2017, no. 2 (31), pp. 14-24. (In Russ., abstr. in Engl.)

70. Bruyako M.G., Kravtsova D.V., Yurchenko V.V., Solov'ev V.G., Ushkov V.A. Vliyanie obrabotki syr'evykh materialov nizkotemperaturnoi neravnovesnoi plazmoi na svoistva stroitel'nykh rastvorov [Influence of processing raw materials withlow-temperature nonequilibrium plasma on the properties of building solutions]. In: Stroitel'nye materialy, 2014, no. 12, pp. 68-71. (In Russ., abstr. in Engl.)

71. Bruyako M.G., Kravtsova D.V., Yurchenko V.V., Ushkov V.A. Vliyanie plazmokhimicheskoi obrabotki vody zatvoreniya na svoistva stroitel'nykh rastvorov [Influence of plasmachemical treatment of mixing water on the properties of building solutions]. In: Promyshlennoe $i$ grazhdanskoe stroitel'stvo [Industrial and Civil Engineering], 2014, no. 4, pp. 45-47. (In Russ., abstr. in Engl.)

72. Ibragimov R.A. Effektivnost' izmel'cheniya kvartsevogo peska $v$ apparate vikhrevogo sloya [Efficiency of grinding quartz sand in the vortexlayer apparatus]. In: Resursoenergoeffektivnye tekhnologii v stroitel'nom komplekse regiona [Resource-efficient technologies in the building complex of the region], 2019, no. 11, pp. 213-216. (In Russ., abstr. in Engl.)

73. Ibragimov R.A., Korolev E.V., Deberdeev R.Ya., Leksin V.V. Optimal'nye parametry $i$ kartina magnitnogo polya rabochei kamery v apparatakh s vikhrevym sloem [0ptimal parameters and picture of the magnetic field of the working chamber in 
devices with a vortexlayer]. In: Stroitel'nye materialy, 2018, no. 7, pp. 64-67. (In Russ., abstr. in Engl.)

74. Ibragimov R.A., Korolev E.V., Kayumov R.A., Deberdeev T.R., Leksin V.V., Sprinke A. Effektivnost' aktivatsii mineral'nykh vyazhushchikh $v$ apparatakh vikhrevogo sloya [Efficiency of activation of mineral binders in vortexlayer apparatuses]. In: Inzhenerno-stroitel'nyi zhurnal [Magazine of Civil Engineering], 2018, no. 6 (82), pp. 191-198. (In Russ., in Engl.)

75. Ibragimov R.A., Korolev E.V., Deberdeev T.R., Leksin V.V. Prochnost' tyazhelogo betona na portlandtsemente, obrabotannom v apparate vikhrevogo sloya [Strength of heavy concrete on Portland cement, processed in a vortex layer apparatus]. In: Stroitel'nye materialy, 2017, no. 10, pp. 28-31. (In Russ., abstr. in Engl.)

76. Askadskii A.A., Van S., Kurskaya E.A., Kondrashchenko V.I., Zhdanova T.V., Matseevich T.A. Vozmozhnosti predskazaniya koeffitsienta termicheskogo rasshireniya materialov na osnove polivinilkhlorida [Possibilities of predicting the coefficient of thermal expansion of materials based on polyvinyl chloride]. In: Stroitel'nye materialy, 2019, no. 11, pp. 57-65. (In Russ., abstr. in Engl.)

77. Askadskii A.A., Matseevich T.A., Kondrashchenko V.I. Raschetnaya skhema dlya otsenki reologicheskikh svoistv polimerov i ikh smesei [Design scheme for assessing the rheological properties of polymers and their mixtures]. In: Stroitel'nye materialy, 2018, no. 10, pp. 64-68. (In Russ., abstr. in Engl.)

78. Grishina A.N., Zemlyakov A.N., Korolev E.V., Okhotnikova K.Yu., Smirnov V.A. Statisticheskoe modelirovanie kak metod vyyavleniya korrozii tsementnykh kompozitov [Statistical modeling as a method for detecting corrosion of cement composites]. In: Vestnik MGSU, 2014, no. 4, pp. 87-97. (In Russ., abstr. in Engl.)

79. Smirnov V.A., Korolev E.V., Evstigneev A.V. Modelirovanie i instrumental'nye sredstva chislennogo analiza $\checkmark$ nanotekhnologii materialovedeniya: obzor [Modeling and instrumental means of numerical analysis in nanotechnology of materials science: a review]. In: Nanotekhnologii v stroitel'stve: nauchnyi internet-zhurnal [Nanobuild.ru], 2014, Vol. 6, no. 5, pp. 34-58. Access mode: http://nanobuild.ru/ru_RU/journal/ Nanobuild-5-2014/34-47.pdf (accessed 08.01.2020). (In Russ.)

80. Smirnov V.A., Korolev E.V., Inozemtsev S.S. Stokhasticheskoe modelirovanie nanoraz-mernykh sistem [Stochastic modeling of nanosized systems]. In: Nanotekhnologii $v$ stroitel'stve: nauchnyi internet-zhurnal [Nanobuild.ru], 2014, Vol. 4, no. 1, pp. 6-14. Access mode: http://nanobuild.
ru/ru_RU/journal/Nanobuild_1_2012_RUS.pdf (accessed 08/03/2020). (In Russ.)

81. Korolev E.V.,Smirnov V.A., Inozemtsev A.S. Dinamicheskoe modelirovanie nanorazmernykh sistem [Dynamic modeling of nanosized systems]. In: Nanotekhnologii v stroitel'stve: nauchnyi internet-zhurnal [Nanobuild.ru], 2012, Vol. 4, no. 3, pp. 26-34. Access mode: http://nanobuild.ru/ru_RU/journal/ Nanobuild_3_2012_RUS.pdf (accessed 07.31. 2020). (In Russ.)

82. Smirnov V.A., Korolev E.V. Ierarkhicheskoe modelirovanie stroitel'nykh materialov kak dispersnykh sistem: spetsializirovannaya programmnaya realizatsiya [Hierarchical modeling of building materials as dispersed systems: specialized software implementation]. In: Stroitel'nye materialy, 2019, no. 1-2, pp. 43-53. (In Russ., abstr. in Engl.)

83. Kondrashchenko V.I. Primenenie metodov komp'yuternogo materialovedeniya $v$ biotekhno-logicheskikh issledovaniyakh [Application of methods of computer material science in biotechnological research]. In: Stroitel'nye materialy, 2006, no. 3, p. 76. (In Russ., abstr. in Engl.)

84. Vorob'ev V.A., Ilyukhin A.V. Osnovnye zadachi komp'yuternogo materialovedeniya stroitel'nykh kompozitov [The main tasks of computer materials science of building composites]. In: Stroitel'nye materialy, 2006, no. 7, pp. 19-21. (In Russ., abstr. in Engl.)

85. Vorob'ev V.A., Vasil'ev Yu.E., Marsov V.I., Bokarev E.I. Vozmozhnosti i perspektivy komp'yuternogo modelirovaniya stroitel'nykh kompozitnykh materialov [Possibilities and prospects of computer modeling of building composite materials]. In: Promyshlennoe i grazhdanskoe stroitel'stvo [Industrial and Civil Engineering], 2012, no. 3, pp. 62-63. (In Russ., abstr. in Engl.)

86. Korolev E.V. Tekhniko-ekonomicheskaya effektivnost' novykh tekhnologicheskikh reshenii. Analiz i sovershenstvovanie [Technical and economic efficiency of new technological solutions. Analysis and improvement]. In: Stroitel'nye materialy, 2017, no. 3, pp. 85-89. (In Russ., abstr. in Engl.)

87. Shapovalov V.I. Modelirovanie sinergeticheskikh sistem. Metod proportsii i drugie matematicheskie metody [Simulation of synergistic systems. Method of proportions and other mathematical methods]. Moscow, Prospekt Publ., 2016, 136 p.

88. Ryb'ev I.A. Stroitel'noe materialovedenie [Building materials science]. Moscow, Vysshaya shkola Publ., 2004, 701 p.

Королев Евгений Валерьевич (Санкт-Петербург). Доктор технических наук, профессор. Проректор по учебно-методической работе ФГБОУ В0 «Санкт-Петербургский государственный архитектурно-строительный университет» (190005, Санкт-Петербург, 2-я Красноармейская ул., д.4. СПбГАСУ).Эл.почта: ekorolev@spbgasu.ru, korolev@nocnt.ru.

Korolev Evgeny V. (St. Petersburg). Doctor of Technical Sciences, Professor. Vice-Rector for Educational and Methodological Work of the Saint Petersburg State University of Architecture and Civil Engineering (4, 2-ya Krasnoarmeyskaya St., St. Petersburg, 190005.SPbGASU).E-mail: ekorolev@spbgasu.ru, korolev@nocnt.ru 